NBER WORKING PAPER SERIES

LEVERAGE, MORAL HAZARD AND LIQUIDITY

\author{
Viral V. Acharya \\ S. Viswanathan \\ Working Paper 15837 \\ http://www.nber.org/papers/w15837 \\ NATIONAL BUREAU OF ECONOMIC RESEARCH \\ 1050 Massachusetts Avenue \\ Cambridge, MA 02138 \\ March 2010
}

This paper was earlier circulated under the title "Moral Hazard, Collateral and Liquidity." We are grateful to Bruno Biais, Patrick Bolton, Peter DeMarzo, Doug Diamond, Darrell Duffie, Daniela Fabbri, Douglas Gale, Itay Goldstein, Nissan Langberg, Arvind Krishnamurthy, Praveen Kumar, Xuewen Liu, Martin Oehmke, Guillaume Plantin, Adriano Rampini, Jean-Charles Rochet, Jose Scheinkman, Raghu Sundaram, Alexei Tchistyi, Dimitri Vayanos and Jiang Wang for useful discussions, to seminar participants at Bank of England, Brunel University, CEPR Symposium (2009) at Gerzensee, Chicago-GSB Conference on Liquidity Concepts, Duke, European Winter Finance Conference (2008) in Klosters, Federal Reserve Bank of New York conference on Liquidity Tools, Houston, Indian School of Business, London Business School, London School of Economics, Michigan, Minnesota, MIT (Sloan), NBER Research Meetings in Market Microstructure, New York Fed-NYU Conference on Financial Intermediation, Northwestern, Oxford, Princeton, Southern Methodist University, Toulouse, Wharton and University College London for comments, and to Ramin Baghai-Wadji, Wailin Yip, Or Shachar and Yili Zhang for their research assistance. Brandon Lindley's help with numerical solutions was particularly helpful. A part of this paper was completed while Viral Acharya was at London Business School and while visiting Stanford-GSB. The usual disclaimer applies. The views expressed herein are those of the authors and do not necessarily reflect the views of the National Bureau of Economic Research.

NBER working papers are circulated for discussion and comment purposes. They have not been peerreviewed or been subject to the review by the NBER Board of Directors that accompanies official NBER publications.

(C) 2010 by Viral V. Acharya and S. Viswanathan. All rights reserved. Short sections of text, not to exceed two paragraphs, may be quoted without explicit permission provided that full credit, including (c) notice, is given to the source. 
Leverage, Moral Hazard and Liquidity

Viral V. Acharya and S. Viswanathan

NBER Working Paper No. 15837

March 2010

JEL No. D53,G20,G30

\begin{abstract}
We build a model of the financial sector to explain why adverse asset shocks in good economic times lead to a sudden drying up of liquidity. Financial firms raise short-term debt in order to finance asset purchases. When asset fundamentals worsen, debt induces firms to risk-shift; this limits their funding liquidity and their ability to roll over debt. Firms may de-lever by selling assets to better-capitalized firms. Thus the market liquidity of assets depends on the severity of the asset shock and the system-wide distribution of leverage. This distribution of leverage is, however, itself endogenous to future prospects.l, Q particular, short-term debt is relatively cheap to issue in good times when expectations of asset fundamentals are benign, resulting in entry to the financial sector of firms with less capital or high leverage. Due to such entry, even though the incidence of financial crises is lower in good times, their severity in terms of de-leveraging and evaporation of market liquidity can in fact be greater.
\end{abstract}

Viral V. Acharya

Stern School of Business

New York University

44 West 4th Street, Suite 9-84

New York, NY 10012

and NBER

vacharya@stern.nyu.edu

S. Viswanathan

Duke University

Fuqua School of Business

1 Towerview Dr

Durham, NC 27708

viswanat@duke.edu 


\title{
Leverage, Moral Hazard and Liquidity
}

\begin{abstract}
We build a model of the financial sector to explain why adverse asset shocks in good economic times lead to a sudden drying up of liquidity. Financial firms raise short-term debt in order to finance asset purchases. When asset fundamentals worsen, debt induces firms to risk-shift; this limits their funding liquidity and their ability to roll over debt. Firms may de-lever by selling assets to better-capitalized firms. Thus the market liquidity of assets depends on the severity of the asset shock and the system-wide distribution of leverage. This distribution of leverage is, however, itself endogenous to future prospects. In particular, short-term debt is relatively cheap to issue in good times when expectations of asset fundamentals are benign, resulting in entry to the financial sector of firms with less capital or high leverage. Due to such entry, even though the incidence of financial crises is lower in good times, their severity in terms of de-leveraging and evaporation of market liquidity can in fact be greater.
\end{abstract}

Keywords: risk-shifting, credit rationing, market liquidity, funding liquidity, fire sales, financial crises, cash-in-the-market pricing.

JEL Classification: G12, G20, D45, D52, D53

\section{Introduction}

"Where did all the liquidity go? Six months ago, everybody was talking about boundless global liquidity supporting risky assets, driving risk premiums to virtually nothing, and now everybody is talking about a global liquidity crunch, driving risk premiums half the distance to the moon. Tell me, Mac, where did all the liquidity go?" - Paul McCulley, PIMCO Investment Outlook, Summer 2007

We argue that the build-up of leverage in the financial sector in good economic times is a key explanation for why adverse asset shocks in such times are associated with severe drying up of liquidity and deep discounts in asset prices. We provide the mechanics of this argument in a model of financial institutions that endogenizes the short-term rollover nature of their debt and examines 
de-leveraging and asset sales as an industry equilibrium phenomenon. In particular, the model illustrates that while the incidence of financial crises is lower when expectations of fundamentals are good, their severity can in fact be greater in such times due to greater system-wide leverage. The model also provides a micro-economic foundation for the linkage between market liquidity, the ease of selling assets at fair prices, and funding liquidity, the ease of rolling over existing debt.

Since the backdrop we have in mind is one of trading-based financial institutions which are typically highly levered, we focus on the agency problem of asset substitution or risk-shifting by borrowers (Jensen and Meckling, 1976) wherein a borrower, after raising debt, has incentives to transfer wealth away from lenders by switching to riskier assets unless the expected profits from safer assets are sufficiently high. Related to the work of Stiglitz and Weiss (1981) and Diamond $(1989,1991)$, this risk-shifting problem rations potential borrowers in that it limits the maximum amount of financing they can raise from lenders. Asset sales provide a mechanism through which borrowers can de-lever and relax the extent of their rationing.

We cast this building block of an individual firm's levering and de-levering in an industry equilibrium. There is a continuum of financial firms which have undertaken some ex-ante debt financing (exogenous initially, endogenized later). At their maturity, these liabilities need to be rolled over. To this end, firms attempt to raise additional debt financing, but its extent is limited due to the risk-shifting problem. The worse the asset-quality shock at the time of rollover (for instance, adverse information about asset's prospects), the lower is the asset's expected profitability to intermediaries, and thus the incentive to risk-shift to higher risk assets is more severe. In anticipation, the greater is the credit rationing of borrowers. Firms that are rationed attempt to de-lever by liquidating some or all of their assets. Assets, however, are specific and can only be acquired by the set of remaining financial firms that has spare debt capacity (as in Shleifer and Vishny, 1992). ${ }^{1}$ The remaining firms can also raise financing against the assets that they buy. However, they have the opportunity to risk-shift too, which limits their financing for asset purchase. Thus, the liquidation price, which is determined by the market-clearing condition, is of the "cash-in-the-market" type (Allen and Gale, 1994): When a large number of firms are liquidating assets, market price is below the expected discounted cash flow and is determined by the distribution of spare debt capacity in the economy.

Crucially, the de-leveraging equilibrium is characterized by the funding liquidity per unit of asset, which is a mirror image of the adversity of the asset shock and the severity of risk-shifting problem: (1) Funding liquidity divides the set of firms into three categories - those that are fully liquidated, those that are partially liquidated, and those that provide liquidity ("arbitrageurs") and purchase assets at fire-sale prices; (2) By determining the opportunity cost of liquidating an asset, funding liquidity also determines the equilibrium extent of de-leveraging of rationed firms;

\footnotetext{
${ }^{1}$ Alternately, one could assume that lenders are short-term debt providers such as money market funds which are constrained by regulation from owning long-term assets.
} 
and (3) Through these first two effects, funding liquidity determines the equilibrium price at which assets are liquidated.

Formally, the equilibrium price of the asset is its funding liquidity plus a measure of the spare debt capacity of the economy, both of which depend on the asset shock and the latter also depends on the distribution of initial leverage in the economy. An interesting result that stems from this characterization of price is that as asset shocks worsen, the moral-hazard intensity increases (i.e., the spread between the return on the good asset and the risk-shifting asset declines), firms' ability to raise financing against assets is lowered and equilibrium levels of spare debt capacity in the economy fall. In turn, the market for assets clears at lower prices. This is simply the result that funding liquidity affects market liquidity (Gromb and Vayanos, 2002 and Brunnermeier and Pedersen, 2009), as both are manifestations of agency problems constraining financial firms' ability to roll over existing debt.

In the preceding discussion, the ex-ante structure of liabilities undertaken by firms was treated as given. We endogenize this structure by assuming that ex ante, firms are ranked by the amount of initial capital they have, or conversely, by the initial external financing they need to fund the project. $^{2}$ The incremental financing is raised through short-term debt contracts that give lenders the ability to liquidate ex post in case promised payments are not met. We show that this shortterm, rollover form of financing of assets that grants control to lenders in case of default (as in collateral and margin requirements, repo financing, borrowing from money-market funds, etc) is optimal from the standpoint of raising maximum ex-ante finance. Intuitively, if lenders do not have the right to liquidate assets, then borrowers can threaten ex post to alter the risk of assets and write down lender claims. In anticipation, lenders will lower the ex-ante liquidity they are prepared to give borrowers. Hence, the efficient contract gives lenders the bargaining power in the form of control rights to liquidate the firm as this maximizes the ex-ante debt capacity.

This augmentation of our benchmark model leads to an interesting and important equilibrium recursion: on the one hand, the promised payment for a given amount of debt financing is decreasing in the level of liquidation prices in case of default; on the other hand, the liquidation price is itself determined by the distribution of promised debt payments since these affect the ex-post rationing and de-leveraging faced by firms. We show that there is a unique solution to this fixed-point recursion, characterized by the fraction of firms that cannot meet their initial financing needs (and are excluded) and by the relation from future asset shocks to corresponding prices. In particular, the downside risk of asset shocks affects the cost of raising leverage and a certain fraction of poorly capitalized firms are unable to enter the financial sector. Therefore, the extent of entry is endogenous to anticipated downside risk.

\footnotetext{
${ }^{2}$ For example, hedge-fund managers, structured purpose vehicles, broker-dealers or investment banks, and commercial banks, must raise different amounts of leveraged financing in order to trade. This kind of ranking of firms by their leverage can be considered as a reduced-form metaphor for richer heterogeneity or regulatory restrictions determining their extent of equity capitalization relative to debt.
} 
While this endogenous entry renders analytical comparative statics difficult, numerical examples using a recursive, constructive algorithm provides an important insight. As the distribution of future asset shocks improves in a first-order stochastic dominance (FOSD) sense, the distribution of funding liquidity improves too, firms face a lower need to de-lever and to engage in fire sales in the future, and, thus, lenders require lower promised payments ex ante. In other words, leverage is "cheap" in good economic times due to lower expected losses from default and even institutions with low levels of initial capitalization can enter the financial sector. Interestingly, there is a robust set of economies for which a better ex-ante distribution of fundamentals is in fact associated with lower prices when adverse shocks to asset quality materialize, compared to prices in the same ex-post states when the economy is facing a worse ex-ante distribution of fundamentals.

This counterintuitive result arises due to endogenous entry in our model. As explained above, good times enable even highly levered institutions to be funded ex ante. Even though bad times are less likely to follow, in case they do materialize, a greater mass of highly levered firms ends up with funding liquidity problems and is forced to de-lever through asset sales. If there is a sufficiently large entry of low-capitalized firms in good times because, for instance, there is abundant flow of liquidity into the financial sector due to global imbalances (Bernanke, 2005), then the effect of de-leveraging can be substantial, generating deep discounts in market prices.

This result explains well the apparent "puzzle" in financial markets that when there is a sudden, adverse asset-quality shock to the economy from a period of high expectations of fundamentals, the drop in asset prices seems rather severe. This phenomenon was highlighted in the introductory quote by Paul McCulley in PIMCO's Investment Outlook of Summer 2007 following the onset of sub-prime crisis when the financial system appeared to switch from expectations of low volatility and abundant global liquidity to one with severe asset-price deterioration and severe drying up of both market and funding liquidity. While there are many elements at work in explaining the complex phenomena characterizing the crisis of 2007-09 (some of which we detail below), our model clarifies that leverage structure of the economy as a whole, in particular, the extent of highly leveraged institutions in the system, is endogenous to expectations leading up to a crisis. The capital structure of financial sector as a whole is crucial to understanding the severity of fire sales that hit asset markets when financial intermediaries attempt to roll over their short-term debt but lenders ration them.

Section 1 provides a backdrop for our theoretical analysis using empirical facts relating to the crisis of 2007-09. Section 2 sets up the benchmark model of risk-shifting and asset sales. Section 3 augments the benchmark model to study the ex-ante debt capacity of firms. Section 4 discusses the related literature. Section 5 concludes. Proofs and the constructive algorithm for solving the fixed-point recursion introduced in Section 3 are in the Appendix. 


\section{Motivation}

Our theoretical analysis is built around (i) the prominence of short-term rollover debt in capital structure of financial firms, (ii) low cost of debt in good economic times which leads to entry of highly leveraged financial firms, and (iii) inability to rollover short-term debt and induced fire sales of assets, especially for highly-levered firms, when adverse shocks materialize. As we explain below, all three of these played an important role in the financial crisis of 2007-09 and the period preceding it.

Starting August 9 2007, the sub-prime crisis took hold of the financial sector. In fact, since the beginning of 2007, information about the deteriorating quality of mortgage assets hit markets on a repeated basis. The impending losses for banks, broker-dealers and hedge funds involved in mortgage-backed assets cast a doubt over the solvency of institutional balance-sheets. An important piece that contributed to the sharp reaction of markets was the highly short-term nature of debt with which these assets, and more broadly balance-sheets, had been financed. In particular, debt was in the form of asset-backed commercial paper (ABCP), repurchase agreements (repos), or unsecured commercial paper (CP) that had to be rolled over at short maturities, often overnight but always less than a few months.

It became progressively clear in the following months that funding conditions had tightened and rollovers of short-term debt would be difficult. To see how sharp was the reaction of financing conditions, Figure 1 Panel $A$ shows the cost of issuing ABCP over the federal funds rate, illustrating that it rose from benign levels of 10 to 15 basis points to over 100 basis points in the months following August 9, 2007. Similarly, Figure 1 Panel B shows the dramatic fall in ABCP outstanding - a measure of financial firms' ability to roll over this debt - whereby in two years from August 2007 the levels reverted from the high of over $\$ 1.2$ trillion to the 2004 level of about just half as such.

Further, there was also substantial liquidation risk. In particular, if assets had to be liquidated, prices would be a far cry from their "fair" or "normal-time" valuations since natural buyers of such assets were themselves hit by the shock to asset quality. This was best epitomized in the suspension of mark-to-market accounting by BNP Paribas' hedge funds on August 9, 2007 whose announcement triggered the ABCP freeze. Though departures of asset prices from their fundamental values are hard to identify conclusively, Figure 2 Panel A shows that the index levels of prices of sub-prime mortgage-backed securities were close to par until Summer of 2007, but declined steadily in the next six months to 40 to 80 cents on a dollar, as funding conditions for financial institutions who held these assets worsened and the market for secondary sales of these assets progressively thinned. Essentially, de-leveraging of the financial sector was ongoing because of the inability to roll over existing debt, emphasized by our model, and the consequent fire sales of assets. 
In the decade preceding the crisis, there had been a secular downward shift in macroeconomic volatility, the so-called "Great Moderation" (Stock and Watson, 2002). As per this explanation, improvements in risk-sharing within and across economies were believed to have stabilized macroeconomic output. There was also a downward revision of asset price volatility as shown in Figure 2 Panel B for levels of VIX, a measure of market volatility implied from option prices. VIX had ranged typically above $20 \%$ prior to 2003 , but remained almost always between $10 \%$ and $20 \%$ up until Summer of 2007. In turn, credit risk of various assets was deemed to have also experienced a fundamental downward revision, enabling issuance of cheaper debt and a build-up of leverage in the financial system.

Indeed, during 2003 to 2 Q 2007, there was substantial entry of new financial intermediaries that were increasingly more levered, and we stress that this was not just a scaling-up of institutions with a given distribution of leverage. In particular, there was an extraordinary growth in the shadow banking sector: structured purpose vehicles which had close to zero capitalization (again, see Figure 1 Panel B), and in balance-sheets of broker-dealers whose leverage rose from assets to equity ratios of 10:1 to 30:1 (Adrian and Shin, 2008). These were funded respectively by short-term $\mathrm{ABCP}$ and $\mathrm{CP}$ or repos, all forms of rollover debt.

And, when the asset shocks to underlying mortgage assets materialized in 2007, the sequence of de-leveraging that ensued, described for example in Acharya, Philippon, Richardson and Roubini (2009), is consistent with the model. Indeed, inability to rollover debt in the form of ABCP, CP and repo "runs" materialized first for worst-capitalized entities, starting with structured purpose vehicles, spreading next to broker-dealers, then to hedge-funds, and finally, to the relatively better-capitalized commercial banks. ${ }^{3}$

These phenomena - build-up of short-term debt in good economic times and entry of highlylevered firms, asset-side shocks that lead to problems in rolling over debt, followed by substantial de-leveraging, fire sales and liquidity discounts in asset prices - are what our model aims to derive as equilibrium outcomes when financial intermediaries have incentives to risk-shift and borrowing contracts endogenously respond to this agency problem.

\footnotetext{
${ }^{3}$ Also consistently with the model's partition of well-capitalized firms as acquirers of assets from highlyleveraged ones, broker-dealers that failed or would have failed were taken over by commercial or universal banks (Bear Stearns by J.P.Morgan Chase, Merrill Lynch by Bank of America, and parts of Lehman Brothers by Barclays and Nomura).
} 


\section{Model}

\subsection{Informal description}

Our model is set up as follows. At date 0 , there is a continuum of agents who have access to identical, valuable trading technology ("asset") of limited size. Agents do not have all of the financing required to incur the fixed costs for setting up firms that will invest in this asset and differ in the amount of personal initial capital they can deploy for investment. They can raise external financing from a set of financiers in order to meet the fixed costs.

Assets are specific in that financiers cannot redeploy them. We assume assets are rendered worthless in hands of financiers unless they sell them right away to those who can deploy them. Conversely, firms are not in the business of providing external finance to each other. Some examples of this setup would be traders setting up hedge funds and borrowing from prime brokers, or broker-dealers financed with short-term commercial paper from money-market funds, although some of our assumptions make the caricature of these settings somewhat extreme.

Each asset produces an uncertain cash flow at date 2. Agents (non-financiers) have the option of switching from their asset to an alternate, riskier asset (e.g., through poor risk management of a trade) that is less valuable but may be attractive once external financing is raised. Such possibility affects the nature and extent of external financing.

At date 1, an observable but non-verifiable public signal concerning the common quality of the valuable assets becomes available. If the optimal contract at date 0 so specifies, financiers may demand repayments at date 1 , or they may effectively roll over their financing to date 2 . An asset sale market exists where assets can be liquidated to other firms at market-clearing prices in exchange for cash that can be used to pay off existing debt. Firms acquiring assets may raise financing at date 1 against existing assets as well as assets to be acquired.

We formally specify and solve the model backwards starting with the second period between date 1 and date 2 . To this end, we first assume and later prove that the optimal date- 0 contract takes the form of debt that is due at date 2 , but it is hard in the sense that it gives financiers (lenders) the control at date 1 to demand early repayment if it is optimal for them to do so. Taking this as an assumption to start with, we next solve the second-period model for a particular realization of the public signal about asset quality.

\subsection{Benchmark second-period model}

The time-line for the model, starting at date 1, is specified in Figure 3. All firm owners and creditors are risk-neutral and the risk-free rate of interest is zero. After raising (new or rolled- 
over) external finance at date 1 , there is the possibility of moral hazard at the level of each firm. In particular, we consider asset-substitution moral hazard. Firm's existing investment is in an asset which is a positive net present value investment. However, after asset sales and raising of external finance at date 1 , each firm can switch its investment to another asset.

We denote the assets as $j, j \in\{1,2\}$, yielding a date- 2 cash flow per unit size of $y_{j}>0$ with probability $\theta_{j} \in(0,1)$, and no cash flow otherwise. We assume that $\theta_{1}<\theta_{2}, y_{1}>y_{2}$, $\theta_{1} y_{1} \leq \theta_{2} y_{2}$, and $\theta_{1} y_{1} \leq \rho_{i}$. In words, the first asset is riskier and has a higher payoff than the second asset, but the second asset has a greater expected value. Also, taking account of the financial liability at date 1 , investing in the first asset is a negative net present value investment for all firms. We assume the shift between assets occurs at zero cost. The simplest interpretation could be a deterioration in the risk-management function of the financial intermediary or outright fraud, that allows pursuit of riskier strategies with the same underlying asset or technology.

The external finance at date 1 is raised in the form of debt with face value of $f$ to be repaid at date 2 . Then, the incentive compatibility condition to ensure that firm owners invest in asset $j=2$ (that is, do not risk-shift to asset $j=1$ ) requires that

$$
\theta_{2}\left(y_{2}-f\right)>\theta_{1}\left(y_{1}-f\right)
$$

This condition simplifies to an upper bound on the face value of new debt:

$$
f<f^{*} \equiv \frac{\left(\theta_{2} y_{2}-\theta_{1} y_{1}\right)}{\left(\theta_{2}-\theta_{1}\right)}
$$

Since this condition bounds the face value of debt that can provide incentives to invest in the better asset, we obtain credit rationing as formalized in the following lemma. This result is by itself not new (see, for example, Stiglitz and Weiss, 1981).

Lemma 1 Firms with liability of $\rho$ at date 1 that is greater than $\rho^{*} \equiv \theta_{2} f^{*}$ cannot roll over debt by only issuing new external finance; that is, they are credit-rationed.

To see this result, note first that $f^{*}<y_{2}$ so that borrowing up to face value $f^{*}$ is indeed feasible in equilibrium provided it enables the borrowing firm to meet its funding needs. In other words, firms with $\rho \leq \rho^{*} \equiv \theta_{2} f^{*}$ borrow, invest in the better asset, and simultaneously meet their funding constraint. Second, note that for $\rho>\rho^{*}$, investment is in the first, riskier asset. However, in this case funding constraint requires that the face value be $\hat{f}=\frac{\rho}{\theta_{1}}$ which is greater than $y_{1}$ for all $\rho>\rho^{*}$. That is, firms with liability $\rho$ exceeding $\rho^{*}$ cannot borrow and are rationed.

Also $\rho^{*}$ is increasing in $\theta_{2}$, the quality of the better asset relative to the riskier one. Economically, $\rho^{*}$ represents the funding liquidity per unit of the asset or the (inverse) moral hazard 
intensity. When the gap between the quality of two assets is large, risk-shifting incentives of asset owners are weak and the asset can sustain greater debt financing. Conversely, if the quality of the better asset deteriorates relative to the riskier asset, then the debt capacity of the asset falls. The funding liquidity $\rho^{*}$, which we treat as a function of asset quality $\theta_{2}$, plays a crucial role in analysis to follow.

We assume in what follows that the continuum of firms is ranked by liabilities $\rho$ such that $\rho \sim g(\rho)$ over $\left[\rho_{\min }, \rho_{\max }\right]$, where $\rho_{\min } \equiv \theta_{1} y_{1}<\theta_{2} y_{2} \leq \rho_{\max }$ and $\rho^{*} \in\left[\rho_{\min }, \rho_{\max }\right]$. Thus, Lemma 1 implies that firms in the range $\left(\rho^{*}, \rho_{\text {max }}\right]$ are credit-rationed in our benchmark model and must "de-lever", that is, engage in asset sales to pay off some or all of their existing debt. ${ }^{4}$

\subsection{Asset sales}

Suppose a firm can sell its assets at a market-clearing price of $p$, which we endogenize later. If firm sells $\alpha$ units of assets, it generates $\alpha p$ as proceeds from asset sale which can be used to repay its debt. The remaining balance-sheet of the firm is of the size $(1-\alpha)$, and its per unit debt capacity is $\rho^{*}$ as in Lemma 1 . Thus, its funding liquidity is given by $\left[\alpha p+(1-\alpha) \rho^{*}\right]$. As long as liquidation price $p$ exceeds the per unit debt capacity of the risky asset $\rho^{*}$, funding liquidity expands with asset sales. We assume and show later that it is indeed the case that $p \geq \rho^{*}$. To raise $\rho$ units in total to roll over debt, the firms must choose a liquidation policy $\alpha \geq 0$ such that

$$
\rho \leq\left[\alpha p+(1-\alpha) \rho^{*}\right]
$$

For firms with $\rho<\rho^{*}$, this constraint is met without engaging any asset sales. For rationed firms of Lemma 1, that is, for $\rho>\rho^{*}$, we obtain the following result:

Proposition 1 If the liquidation price $p$ is greater than $\rho^{*}$, then asset sales relax credit rationing for firms with $\rho \in\left(\rho^{*}, p\right]$, and firm with liability $\rho$ engages in asset sale of $\alpha$ units, where

$$
\alpha(p, \rho)=\frac{\left(\rho-\rho^{*}\right)}{\left(p-\rho^{*}\right)} .
$$

Thus, asset sales increase in a firm's liability $\rho$ and decrease in liquidation price $p$.

\footnotetext{
${ }^{4} \mathrm{~A}$ relevant issue is if a firm make a collateralized loan instead of selling the asset. This issue is intimately related to the issue of asset-specificity. The only way a lender can ensure there is no risk-shifting possibility with a collateralized asset is to manage the assets himself. We effectively assume this would cause asset values to depreciate to zero. Alternately, the lender can take the asset as collateral and delegate the asset management to a third party in the financial sector, but then we are back to the risk-shifting problem and the argument repeats.
} 
The liquidation price $p$ plays a crucial role in determining the extent of asset sales or deleveraging. In particular, if liquidation price is low, then firms have to liquidate a large part of their existing investment. Next, we introduce a market for liquidation of the asset at date 1 and study how it influences and is influenced by the equilibrium level of asset sales. Also, we assumed in the analysis above that $p \leq \rho_{\max }$. We verify below that this will indeed be the case under our maintained assumption $\theta_{2} y_{2} \leq \rho_{\max }$.

\subsection{Market for asset sales}

Assets liquidated by firms that face rationing $\left(\rho>\rho^{*}\right)$ are acquired by those that are not rationed $\left(\rho<\rho^{*}\right)$ and have spare debt capacity. We consider standard market clearing for asset sales. An important consideration is that asset purchasers, by virtue of their smaller liabilities, may be able to raise liquidity not only against their existing assets but also against assets they will acquire.

Formally, suppose that a non-rationed firm with liability $\rho$ acquires $\alpha$ units of assets. Then, the total liquidity available to the firm for asset purchase is given by

$$
l(\alpha, \rho)=\left[(1+\alpha) \rho^{*}-\rho\right] .
$$

That is, the funding ability of a non-rationed firm consists of its spare debt capacity from existing assets, $\left(\rho^{*}-\rho\right)$, plus the liquidity that can be raised against assets to be acquired, $\alpha \rho^{*}$.

The pertinent question is: How many units of assets would this firm be prepared to buy as a function of the price $p$ ? Note that no firm would acquire assets at a price higher than their expected payoff. Denoting this price as $\bar{p}=\theta_{2} y_{2}$, we obtain the following demand function $\hat{\alpha}(p, \rho)$ for the firm. For $p>\bar{p}, \hat{\alpha}=0$. For $p<\bar{p}, \hat{\alpha}$ is set to its highest feasible value given the liquidity constraint $p \hat{\alpha}=l(\hat{\alpha}, \rho)$, which simplifies to

$$
\hat{\alpha}(p, \rho)=\frac{\left(\rho^{*}-\rho\right)}{\left(p-\rho^{*}\right)} .
$$

Finally, for $p=\bar{p}$, buyers' demand is indifferent between 0 and $\hat{\alpha}$ (evaluated at $\bar{p}$ ).

Thus, the total demand for assets for $p<\bar{p}$ is given by

$$
D\left(p, \rho^{*}\right)=\int_{\rho_{\min }}^{\rho^{*}} \hat{\alpha}(p, \rho) g(\rho) d \rho=\int_{\rho_{\min }}^{\rho^{*}} \frac{\left(\rho^{*}-\rho\right)}{\left(p-\rho^{*}\right)} g(\rho) d \rho,
$$

where we have stressed the dependence on funding liquidity $\rho^{*}$.

Given this demand function for non-rationed firms, we can specify the market-clearing condition. Note that the total supply of assets up for liquidation is given by

$$
S\left(p, \rho^{*}\right)=\int_{\rho^{*}}^{\rho_{\max }} \min \left[\frac{\left(\rho-\rho^{*}\right)}{\left(p-\rho^{*}\right)}, 1\right] g(\rho) d \rho
$$


The two terms correspond respectively to (i) partial asset liquidations by firms with $\rho \in\left(\rho^{*}, p\right]$ to meet their liabilities, and (ii) complete liquidation of firms with $\rho \in\left(p, \rho_{\max }\right]$ which cannot fully meet their liabilities. Then, the equilibrium price $p^{*}$ satisfies the market-clearing condition

$$
E\left(p, \rho^{*}\right) \equiv D\left(p, \rho^{*}\right)-S\left(p, \rho^{*}\right)=0 .
$$

If excess demand is positive for all $p<\bar{p}$, then $p^{*}=\bar{p}$ (since buyers are indifferent at this price between buying and not buying, and their demand can be set equal to the supply).

Before characterizing the behavior of the equilibrium price, it is useful to consider properties of the demand and supply functions. First, both demand and supply functions decline in price $p$. This is because as price increases, asset purchasers can only buy fewer assets given their limited liquidity. Simultaneously, rationed firms need to liquidate a smaller quantity of their assets. Hence, what is important is the behavior of excess demand function, $E\left(p, \rho^{*}\right)$, as a function of price $p$. We focus below on the case where $p<\bar{p}$, the details of the case where $p=\bar{p}$ are in the Appendix (in Proof of Proposition 2).

The excess demand function can be rewritten as:

$$
E\left(p, \rho^{*}\right)=D\left(p, \rho^{*}\right)-S\left(p, \rho^{*}\right)=\int_{\rho_{\min }}^{\rho_{\max }} \max \left[\frac{\left(\rho^{*}-\rho\right)}{\left(p-\rho^{*}\right)},-1\right] g(\rho) d \rho
$$

Integrating this equation by parts yields

$$
E\left(p, \rho^{*}\right)=-1+\frac{1}{\left(p-\rho^{*}\right)} \int_{\rho_{\min }}^{p} G(\rho) d \rho
$$

where $G(\rho)=\int_{\rho_{\min }}^{p} g(\rho) d \rho$ and $G\left(\rho_{\min }\right)=0$.

The condition that excess demand be zero, i.e., $E\left(p, \rho^{*}\right)=0$, leads to the relationship

$$
p=\rho^{*}+\int_{\rho_{\min }}^{p} G(\rho) d \rho .
$$

If the solution to this equation exceeds $\bar{p}$, excess demand is positive for all $p<\bar{p}$ and thus $p^{*}=\bar{p}$.

First, from this representation of market-clearing condition, we observe that the price can never fall below the threshold level of $\rho^{*}$ (as we assumed earlier while deriving Proposition 1 ). This is because non-rationed firms can always raise $\rho^{*}$ of liquidity against each additional unit of asset they purchase. Hence, at $p=\rho^{*}$, their demand for asset purchase is infinitely high. The second term captures the effect of spare liquidity in the system. Intuitively, if this spare liquidity is high, then the price is at its frictionless value of $\bar{p}$, else it reflects a fire-sale discount.

Second, the price can never be higher than $\bar{p}$, as above this price demand is zero and there can be no market clearing. Together, these two facts guarantee an interior market-clearing price 
$p^{*} \in\left[\rho^{*}, \bar{p}\right]$. Third, as intuition would suggest, the excess demand function is strictly decreasing in $p$ at the market clearing price $p^{*}$, which yields a unique $p^{*}$. And, finally, the key determinant of the market-clearing price is the funding liquidity per unit of the asset, $\rho^{*}$. This parameter partitions firms into rationed firms and non-rationed firms; hence, the extent of buying power of non-rationed firms, and, also, the extent of asset liquidations.

Thus, the equilibrium price satisfies the following proposition:

Proposition 2 The market-clearing price for asset sales, $p^{*}$, is unique and weakly increasing in the funding liquidity $\rho^{*}$ in the following manner:

(i) There exists a critical threshold $\hat{\rho}^{*}<\bar{p}$ such that $p^{*}=\bar{p}, \forall \rho^{*} \geq \hat{\rho}^{*}$; and,

(ii) For $\rho^{*}<\hat{\rho}^{*}, p^{*} \in\left[\rho^{*}, \bar{p}\right), p^{*}$ is strictly increasing in $\rho^{*}$, and $p^{*}=\rho^{*}$ only when $\rho^{*}=\rho_{\min }$. Therefore, in this region, there is an illiquidity discount, $\left[\bar{p}-p^{*}\right]$, whose size is declining in $\rho^{*}$.

When $\rho^{*}$ is above a critical value $\hat{\rho}^{*}>\rho_{\min }$, assets are liquidated at their highest valuation: few firms are rationed, buyers (non-rationed firms) have a lot of liquidity and sellers (rationed firms) do not need to de-lever much. As the incentives to risk-shift increase, that is, $\rho^{*}$ declines, there is not enough liquidity in the system to absorb the pool of assets being put up for liquidation at the highest price. Hence, the market-clearing price is lower than $\bar{p}$. Since assets are "cheap", non-rationed firms demand as much as possible of the liquidated assets with their entire available liquidity. On the supply side, as price falls, more firms are rationed, and rationed firms must liquidate more. As the risk-shifting incentives increase ( $\rho^{*}$ becomes smaller), prices fall until eventually they hit $\rho^{*}$, and this happens when in fact $\rho^{*}$ equals $\rho_{\min }$.

The liquidation price exhibits "cash-in-the-market pricing" as in Allen and Gale $(1994,1998)$ since it depends on the overall amount of liquidity available in the system for asset purchases, which, in turn, is determined by the risk-shifting incentives. The important message from this analysis is that whether a rationed firm can relax its own borrowing constraint by selling assets depends upon the liquidity of the potential purchasers of its assets (through the liquidation price) and on the liquidation of assets by other such rationed firms. Thus, one can think of the excess demand for the asset, $E\left(p, \rho^{*}\right) \equiv\left[D\left(p, \rho^{*}\right)-S\left(p, \rho^{*}\right)\right]$, given by equation (10), as an inverse measure of the excess financial leverage in the system. ${ }^{5}$

Another important observation is that part (ii) of Proposition 2 implies a natural link between funding liquidity of firms and liquidity of asset markets. Funding liquidity in our model is measured by $\rho^{*}$. Market illiquidity can be measured as the fire-sale discount in prices, $\left[\bar{p}-p^{*}\right]$. The

\footnotetext{
${ }^{5}$ These features of our model are essentially variants of the industry-equilibrium effects in Shleifer and Vishny (1992)'s model. Crucially, however, the determinants of rationing and of the limited ability of buyers to purchase are both tied to the same underlying state variable, the extent of risk-shifting problem.
} 
Proposition formally shows that funding liquidity and market illiquidity are negatively related. ${ }^{6}$ Unlike the extant literature where funding liquidity is modeled through exogenously specified margin or collateral requirements, our measure of funding liquidity is linked to the amount of financing that can be raised given the risk-shifting problem tied to leverage.

We combine Proposition 2 with Proposition 1 to obtain the result that the extent of asset sales required by a rationed firm is higher when asset's funding liquidity is lower.

Proposition 3 The extent of asset sale by firm with liability $\rho$, denoted as $\alpha(\rho)$, is decreasing in the funding liquidity $\rho^{*}$.

The following example which assumes a uniform distribution on the liabilities helps us illustrate these equilibrium relationships graphically.

Example: Suppose that $\rho \sim \operatorname{Unif}\left[\rho_{\min }, \rho_{\max }\right]$ and $\bar{p}=\theta_{2} y_{2}=\rho_{\max }$. Then, solving the market-clearing condition $E\left(p, \rho^{*}\right)=0$, yields the following equilibrium relationships:

1. If $\rho^{*} \geq \hat{\rho}^{*} \equiv \frac{1}{2}\left(\rho_{\min }+\rho_{\max }\right)$, then the price for asset sales is $p^{*}=\rho_{\max }$;

2. If $\rho^{*}<\frac{1}{2}\left(\rho_{\min }+\rho_{\max }\right)$, then there is cash-in-the-market pricing:

$$
p^{*}=\rho_{\max }-\sqrt{\left(\rho_{\max }-\rho_{\min }\right)} \sqrt{\left(\rho_{\max }+\rho_{\min }-2 \rho^{*}\right)} .
$$

3. In the cash-in-the-market pricing region, the equilibrium price $p^{*}$ is increasing and convex in funding liquidity $\rho^{*}: \frac{d p^{*}}{d \rho^{*}}>0$ and $\frac{d^{2} p^{*}}{d \rho^{* 2}}>0$.

The price $p^{*}$ and the amount of leverage repaid, that is, asset sale proceeds $\alpha(\rho) p$, are illustrated in Figure 4. Figure 4 Panel A shows cash-in-the-market pricing when funding liquidity is below $\hat{\rho}^{*}$. Figure 4 Panel B is striking. ${ }^{7}$ As the risk-shifting incentives increase ( $\rho^{*}$ falls), a smaller range of firms is able to relax rationing and at the same time these firms face increasingly greater de-leveraging. Finally, Figure 4 Panel $\mathrm{C}$ plots market illiquidity, measured as the fire-sale discount in asset price, $\left[\bar{p}-p^{*}\right]$, as a function of the funding liquidity $\rho^{*}$. It illustrates that when funding liquidity is high, market liquidity is at its maximal level. As funding liquidity deteriorates and falls below $\hat{\rho}^{*}$, market becomes illiquid and increasingly so as funding liquidity deteriorates.

Interpretation of funding liquidity or (inverse) moral hazard intensity: What does it mean to vary the parameter $\rho^{*}$ ? Recall that $\rho^{*}=\left[\theta_{2}\left(\theta_{2} y_{2}-\theta_{1} y_{1}\right)\right] /\left(\theta_{2}-\theta_{1}\right)$, so that $\rho^{*}$ is increasing

\footnotetext{
${ }^{6}$ While the link here is only from funding liquidity to market liquidity, our augmented model of Section 3 will also formalize the reverse link from market liquidity to (ex-ante) funding liquidity.

${ }^{7}$ The parameters are: $\theta_{2}=0.8, y_{2}=12.5, \theta_{1}=0.2, y_{1}=20$, giving $\rho_{\max }=10$ and $\rho_{\min }=4$.
} 
in $\theta_{2}$, the quality of the better asset. Thus, a decrease in $\rho^{*}$ can be given the economically interesting interpretation of a deterioration in the quality of assets, for example, over the business cycle. Note that we are holding constant the quality of bad asset $\theta_{1}$. So strictly speaking, if the better asset deteriorates in quality in a relative sense compared to the other asset during a business-cycle downturn, then the risk-shifting problem gets aggravated: asset can sustain a smaller amount of debt capacity as incentives arising from higher profits of the better asset are weakened. Therefore, the model entertains a natural interpretation that during economic downturns and following negative shocks to the quality of assets, there is lower funding liquidity, and thus, greater credit rationing and de-leveraging in the economy. Accompanying these are lower prices for asset liquidations not just due to the deterioration in asset quality but also due to market illiquidity or the reduced capacity of potential buyers to acquire assets (as their funding liquidity is lowered too).

In our analysis so far, we assumed the distribution of liabilities was unrelated to the quality of assets. Relaxing this would formally imply a relationship between $\theta_{2}$ and the distribution of liquidity shocks $g(\rho)$. We build this link by analyzing the date- 0 structure of the model.

\section{Ex-ante debt capacity}

In this section, we provide an equilibrium setting that yields the structure of liabilities $\rho_{i}$ taken as given so far. We start with a summary of what this section achieves.

We endogenize the structure of liabilities by assuming that at date 0 , firms are ranked by their initial wealth or capital levels and must raise incremental financing to make a fixed level of investment (identical for all firms) in order to trade. The incremental financing is raised through short-term debt contracts, payable at date 1 . Asset quality $\left(\theta_{2}\right)$, taken as given so far, is now uncertain when viewed from date 0 . Depending on the interim signal of asset quality at date 1 , borrowers may not be able to pay off promised payments to lenders. Debt contracts give lenders the ability to liquidate ex post in case of default (as in collateral and margin requirements). We show that this contract is in fact optimal from the standpoint of raising maximum ex-ante finance.

This augmentation of the benchmark model leads to an important equilibrium recursion: on the one hand, the promised payment for a given amount of financing is decreasing in the level of liquidation prices; on the other hand, the liquidation price is itself determined by the distribution of promised debt payments to be met by firms. We show in Section 3.2 that there is a unique solution to this recursion, characterized by the fraction of firms that are ex-ante rationed (that is, firms that are unable to raise enough debt to meet the fixed costs) and the ex-post relation from realized asset quality to funding liquidity, and, in turn, to asset price. In particular, for low realizations of asset quality, borrower incentives to risk-shift are high, funding liquidity is 
low, there is greater de-leveraging in the economy, and potential buyers also face tighter funding constraints, all of which lowers the market-clearing price.

While the ex-ante rationing of firms renders analytical results on comparative statics difficult, numerical examples in Section 3.3 help answer the primary question at hand in this paper: how does market liquidity get affected when adverse asset shocks (formally, low realized values of $\theta_{2}$ ) materialize from good economic times that are characterized by ex-ante expectations of asset shocks that are benign (formally, better ex-ante distributions of $\theta_{2}$ )?

\subsection{The set-up}

The augmented time-line is specified in Figure 5. Suppose that at date 0, there is a continuum of firms that have access to an investment opportunity with identical payoffs. However, each firm has to raise a different amount of external finance in order to access the opportunity, for example, due to differing levels of internal capital. We assume that the investment shortfall of firm $i$ is externally financed via a debt contract with a fixed, promised payment of $\rho_{i}$ at date 1 , against which creditors provide financing of $s_{i}$; the ex-ante cumulative distribution function of $s_{i}$ is given by $R\left(s_{i}\right)$ over $\left[s_{\min }=\theta_{1} y_{1}, s_{\max }\right]$. This assumption on the range of $s_{i}$ ensures that no debt less than the value of the bad (riskier) project is issued.

The investment opportunity can yield in two periods (date 2 ) a cash flow $y_{2}$ with probability $\theta_{2}$. However, after issuance of rollover debt and asset sales at date 1 , there is the possibility of risk-shifting. Firm owners, if optimal to do so, may switch from the existing safer asset to the riskier asset, which yields a cash flow $y_{1}$ with probability $\theta_{1}$, where we we assume as in the benchmark model that $\theta_{1}<\theta_{2}, y_{1}>y_{2}$, and $\theta_{1} y_{1}<\rho_{i} \leq \theta_{2} y_{2}$. Viewed from date $0, \theta_{2}$ is uncertain: $\theta_{2}$ has a cumulative distribution function (cdf) $H\left(\theta_{2}\right)$ and probability density function (pdf) $h\left(\theta_{2}\right)$ over $\left[\theta_{\min }, \theta_{\max }\right]$, where we assume for simplicity that $\theta_{\min } y_{2} \geq \theta_{1} y_{1}$, that is, the worst-case expected outcome for the safer asset is no worse than that for the riskier asset. In fact we impose that

$$
\theta_{\min }=\frac{\theta_{1} y_{1}}{y_{2}}\left[1+\sqrt{1-\frac{y_{2}}{y_{1}}}\right] \text {. }
$$

This assumption ensures that maximum amount that can be borrowed per unit asset is $\rho^{*}$ (which is always higher than $\left.\theta_{1} y_{1}\right){ }^{8}$

Firms can attempt to meet the promised payment $\rho_{i}$ at date 1 by rolling over existing debt or equivalently by issuing new debt. Firms may also de-lever by selling assets. Note that $\rho_{i}$ is fixed in that it is not contingent on the realization of $\theta_{2}$, which we assume is observable but

\footnotetext{
${ }^{8}$ This assumption is made to simplify exposition and can be relaxed.
} 
not verifiable. If the payment $\rho_{i}$ cannot be met at date 1 , then there is a transfer of control to creditors who liquidate the assets and collect the proceeds.

Thus, for a given realization of $\theta_{2}$, the date- 1 structure of the augmented model embeds the date- 1 structure of the benchmark model where liabilities $\rho_{i}$, and their range and distribution across firms were taken as given. In particular, the lower the realization of $\theta_{2}$, the greater is the risk-shifting problem, and the lower is the per unit debt capacity of the asset at date 1 , denoted as $\rho^{*}\left(\theta_{2}\right)$. Thus, $\theta_{2}$ indexes fundamental information that determines the funding liquidity conditions in future.

We show next that the distribution of investment shortfall $s_{i}$ at date 0 translates into an equilibrium distribution of date- 1 promised debt payments $\rho_{i}$. Consider a particular realization of interim signal, say $\theta_{2}$, at date 1 . As shown in Proposition 1, firms with liabilities up to $\rho^{*}\left(\theta_{2}\right)$ $=\left[\theta_{2}\left(\theta_{2} y_{2}-\theta_{1} y_{1}\right)\right] /\left(\theta_{2}-\theta_{1}\right)$ are not rationed. These firms can meet their outstanding debt payments at date 1 and possibly also acquire more assets. Next, as also shown in Proposition 1 , firms with liabilities in the range $\left(\rho^{*}\left(\theta_{2}\right), p^{*}\left(\theta_{2}\right)\right]$ are able to meet their debt payments but only by de-leveraging through asset sales. These firms can also meet their outstanding debt payments at date 1 but need to scale down their asset holdings and do not have spare liquidity to acquire more assets. Finally, firms with liabilities greater than $p^{*}\left(\theta_{2}\right)$ cannot meet their outstanding debt payments, and creditors liquidate these firms' assets.

Then, since date- 0 creditors are risk-neutral, the amount of financing $s_{i}$ that firm $i$ can raise at date 0 , satisfies the creditors' individual rationality constraint:

$$
s_{i}=\int_{\theta_{\min }}^{p^{*-1}\left(\rho_{i}\right)} p^{*}\left(\theta_{2}\right) h\left(\theta_{2}\right) d \theta_{2}+\int_{p^{*-1}\left(\rho_{i}\right)}^{\theta_{\max }} \rho_{i} h\left(\theta_{2}\right) d \theta_{2},
$$

which captures the fact that for sufficiently low realizations of $\theta_{2}$, the firm ends up being rationed enough that it is unable to meet debt payments and is liquidated, whereas for high realizations of $\theta_{2}$, debt payments are met. The critical threshold determining whether $\theta_{2}$ realization is "low" or "high" for firm $i$ is given implicitly by the relation: $\rho_{i}=p^{*}\left(\theta_{2}\right)$. Also implicit in equation (14) is the fact that some low-capital (high-shortfall) borrowers may be excluded altogether from the financial sector at date 0 since the amount owed $s_{i}$ may not be covered by the maximum amount available for payment the next period.

Given a price function $p^{*}\left(\theta_{2}\right)$ and financing $s_{i}$, equation (14) implicitly gives the face value $\rho_{i}$ that the firm must pledge to its creditors. However, we need to take account of Proposition 2 and recognize that the market-clearing price $p^{*}\left(\theta_{2}\right)$ itself depends upon the entire distribution of liabilities $\rho_{i}$ across firms. In case a firm is in default, creditors recover an amount that depends upon the asset liquidation price, and, thus on the liabilities of other firms; in turn, each firm's ex-ante debt capacity depends on the expectation over the amount recovered. ${ }^{9}$

\footnotetext{
${ }^{9}$ This aspect of the model can be viewed as a general version of Shleifer and Vishny (1992) industry-equilibrium
} 
With this background, we define the equilibrium of the ex-ante borrowing stage. An important notational issue to bear in mind is that in the benchmark model, we assumed as exogenously given the distribution of liabilities, $G(\rho)$, but in the augmented model, this distribution is induced by the exogenously given distribution of financing needs, $R(s)$.

Definition of ex-ante equilibrium: A dynamic equilibrium of our set up is (i) a pair of functions $\rho\left(s_{i}\right)$ and $p^{*}\left(\theta_{2}\right)$, which respectively give the promised face-value for raising financing of $s_{i}$ units at date 0 , and the equilibrium price at date 1 given interim signal of asset quality of $\theta_{2}$; and (ii) a truncation point $\hat{s}$, which is the maximum amount of financing that a firm can raise at date 0 , such that $\rho\left(s_{i}\right), p^{*}\left(\theta_{2}\right)$ and $\hat{s}$ satisfy the following fixed-point recursion:

1. For every $\theta_{2}$, asset price is determined by the funding liquidity of asset and spare debt capacity in the financial sector (the industry equilibrium condition of Proposition 3):

$$
p^{*}\left(\theta_{2}\right) \leq \rho^{*}\left(\theta_{2}\right)+\int_{\rho_{\min }}^{p^{*}\left(\theta_{2}\right)} \hat{G}(u) d u
$$

where compared to equation (12), we have replaced distribution of liabilities $G(\cdot)$ with the distribution $\hat{G}(\cdot)$ and also substituted the variable of integration $\rho$ with $u$ to avoid confusion with the function $\rho\left(s_{i}\right)$. In particular, $\hat{G}(u)$ is the truncated equilibrium distribution of liabilities given by $\hat{G}(u)=\frac{R\left(\rho^{-1}(u)\right)}{R(\hat{s})}$. Formally, $\hat{G}(u)$ is induced by the distribution of financing amounts, $R(s)$, via the function $\operatorname{Prob}\left[\rho\left(s_{i}\right) \leq u \mid s_{i} \leq \hat{s}\right]$. As in case of equation $(12)$, a strict $(<)$ inequality in equation (15) leads to $p^{*}\left(\theta_{2}\right)=\bar{p}\left(\theta_{2}\right)=\theta_{2} y_{2}$.

2. Given the price function $p^{*}\left(\theta_{2}\right)$, for every shortfall $s_{i} \in[0, \hat{s}]$, the promised face value $\rho$ is determined by the requirement that lenders receive in expectation the amount being lent:

$$
s_{i}=\int_{\theta_{\min }}^{p^{*-1}(\rho)} p^{*}\left(\theta_{2}\right) h\left(\theta_{2}\right) d \theta_{2}+\int_{p^{*-1}(\rho)}^{\theta_{\max }} \rho h\left(\theta_{2}\right) d \theta_{2} .
$$

3. The truncation point $\hat{s}$ for maximal external financing is determined by the condition

$$
\hat{s} \leq \int_{\theta_{\min }}^{\theta_{\max }} p^{*}\left(\theta_{2}\right) h\left(\theta_{2}\right) d \theta_{2}
$$

with a strict inequality implying that $\hat{s}=s_{\max }$ (all borrowers are financed). ${ }^{10}$

model of debt capacity.

${ }^{10}$ For future reference, we note that differentiating equality versions of equations (15) and (16) yields alternative 


\subsection{The solution}

We prove that there is a unique dynamic equilibrium that solves the fixed-point recursion stated above and provide an explicit characterization of the solution.

In what follows, we suppress the subscript $i$ unless it is necessary. Also, it is easier to analyze the equilibrium recursion by working with the inverse functions $s(\rho)$ and $\theta_{2}(p)$. Here $s(\rho)$ gives the financing raised ex ante for a given face-value $\rho$ while $\theta_{2}(p)$ gives the realization of the state $\theta_{2}$ for a given equilibrium price $p .{ }^{11}$ A solution to the fixed-point recursion exists and is unique; we state the result as a formal proposition below and focus on the economic properties of the fixed-point. The technical details are relegated to the Appendix.

Proposition 4 There exists a unique solution to the dynamic equilibrium defined in Section 3.1:

1. Given a maximal borrowing amount $\hat{s}$, the borrowing $s(\rho)$ as a function of face value is given by the unique solution to the (integro-differential) equation: ${ }^{12}$

$$
\frac{d s}{d \rho}=1-H\left(\max \left\{\frac{\left(\theta_{1} y_{1}+L(\rho)\right)+\sqrt{\left(\theta_{1} y_{1}+L(\rho)\right)^{2}-4 y_{2} L(\rho) \theta_{1}}}{2 y_{2}}, \frac{\rho}{y_{2}}\right\}\right)
$$

with the end-point constraint that $s\left(\theta_{1} y_{1}\right)=\theta_{1} y_{1}$.

2. Given $s(\rho)$, the inverse equilibrium price function $\theta_{2}(p)$ is uniquely given by

$$
\theta_{2}(p)=\max \left\{\frac{\left(\theta_{1} y_{1}+L(p)\right)+\sqrt{\left(\theta_{1} y_{1}+L(p)\right)^{2}-4 y_{2} L(p) \theta_{1}}}{2 y_{2}}, \frac{p}{y_{2}}\right\}
$$

over the domain $\left[\theta_{1} y_{1}, \theta_{\max } y_{2}\right]$.

3. The maximal borrowing amount is uniquely given by the boundary condition

$$
\hat{s} \leq \int_{\theta_{\min }}^{\theta_{\max }} p\left(\theta_{2}\right) h\left(\theta_{2}\right) d \theta_{2}
$$

but equivalent conditions:

$$
\begin{aligned}
\frac{d p}{d \theta_{2}} & =\frac{\frac{d \rho^{*}\left(\theta_{2}\right)}{d \theta_{2}}}{1-\hat{G}(p)} \text { if } p<\theta_{2} y_{2}, \text { else } \frac{d p}{d \theta_{2}}=y_{2}, \text { and } \\
\frac{d \rho}{d s_{i}} & =\frac{1}{1-H\left(p^{*-1}(\rho)\right)} \text { if } \rho \geq p^{*}\left(\theta_{\min }\right), \text { else } \frac{d \rho}{d s_{i}}=1
\end{aligned}
$$

${ }^{11}$ Since these are one-to-one functions, we can follow this approach. Notice that both $\rho$ and $p$ have the domain $\left[\theta_{1} y_{1}, \theta_{\max } y_{2}\right]$ (one cannot have a face value higher than the highest possible price); it is possible that the upper bound is not reached in equilibrium and we account for this.

${ }^{12}$ Define $L(\rho)=\rho-\int_{\theta_{1} y_{1}}^{\rho} \hat{G}(u) d u$. 
where $p\left(\theta_{2}\right)$ is implicitly also function of $\hat{s}$.

The solution to the fixed-point recursion is a contraction and can be used to compute the equilibrium using a recursive algorithm outlined in the Appendix. Next, we compute numerical examples to answer why the drying up of liquidity is more severe when crises emanate from good economic times.

\subsection{Severity of crises in good economic times}

An apparent "puzzle" in financial markets is that when there is a sudden, adverse asset-quality shock to the economy from a period of high expectations of fundamentals, the drop in asset prices seems rather severe. This is perhaps best epitomized by the crisis of 2007-09, which was preceded during 2003 to 2Q 2007 by a period of extraordinary benign conditions (Figures 1 and 2). This phenomenon was also highlighted in the introductory quote based on remarks by Paul McCulley in PIMCO's Investment Outlook of Summer 2007, which argued that at the onset of sub-prime crisis, the financial system appeared to switch from expectations of low volatility and abundant global liquidity to one with severe asset-price deterioration and severe drying up of both market and funding liquidity. While there is no explicit role for "volatility" in our model, we ask a related question: Does a better date- 0 distribution of future asset quality shocks lead to greater market and funding liquidity problems at date 1 ? We explain below that somewhat counter-intuitively, the answer to this question in our model is yes.

To understand why, we solve two numerical examples using the recursive algorithm provided in the Appendix to compute the date- 0 equilibrium. In both numerical examples, we consider a situation where the distribution of asset quality improves in a first-order stochastic dominance (FOSD) sense. Such comparative statics are in general ambiguous in the model because of the effect of endogenous entry (the last marginal project that can be financed depends on economy's parameters), as an improvement in the expectation of fundamentals (FOSD increase in the distribution of $\theta_{2}$ ) has two countervailing effects.

The first effect of improvement in fundamentals is to weakly increase expected prices at date 1 , for a given pool of firms financed at date 0 . Simply, downside risk is less likely. This increase in expected prices lowers creditors' losses in default, and hence, the cost of debt. Formally, $\rho(s)$ is lower in good times for any given $s$. This, however, leads to an interesting second effect. The lower cost of debt results in the pool of firms financed at date 0 to expand to include higher leverage firms. Or formally, the maximal shortfall that can be financed, $\hat{s}$, is higher in good times. In other words, the starting capital structure of the economy is endogenous to expectations of fundamentals: in good times, debt is cheap and there is entry of low-capital or high-leverage institutions in the financial sector. We show below that this endogeneity of entry and capital 
structure implies that even though adverse asset shocks are less likely to materialize in good times (given the FOSD characterization of good economic times), in case they do, then there is greater de-leveraging in the economy and market-clearing prices for asset sales can sometimes be lower than when the same adversity of shocks materializes in bad times.

In an example that delivers this counterintuitive insight, we let:

a) $s_{\min }=\theta_{1} y_{1}=0.2, s_{\max }=1, y_{1}=4, y_{2}=1, \theta_{1}=0.05$, so that $s$ has support $[0.2,1]$; and, b) $t=0.8$ (which is also the value of $s_{\max }-s_{\min }$ ) and suppose that the distribution of financing shortfalls in the financial sector is distributed uniformly as

$$
R(s)=\frac{s-0.2}{t}
$$

c) $\theta_{2}$ to be distributed as $H(\theta)$ on $\left[\theta_{\min }, \theta_{\max }\right]$ such that ${ }^{13}$

$$
H(\theta)=1-\left(1-\frac{\theta-\theta_{\min }}{\theta_{\max }-\theta_{\min }}\right)^{1 / \gamma}
$$

where $\gamma, \gamma>0$ (note that $\gamma=1$ corresponds to the uniform distribution). A higher value of $\gamma$ implies first-order stochastic dominance (FOSD); in fact for any truncation $\hat{s}$, the maximal shortfall that can be financed in the economy, a higher value of $\gamma$ implies FOSD. ${ }^{14}$ Also, note that $E[\theta]$ is $\theta_{\min }+\left[\left(\theta_{\max }-\theta_{\min }\right) \gamma\right] /[1+\gamma]$ which is increasing in $\gamma$. We let $\gamma$ take values in $\{0.5,5.0\}$. So $\gamma=0.5$ corresponds to bad economic times and $\gamma=5.0$ to good economic times.

We show for these values the distributions of the promised face-value ("cost") of leverage, $\rho(s)$, in one plot (Figure 6 Panel $\mathrm{A}$ ) and the market-clearing price, $p(\theta)$, in another plot (Figure 6 Panel B). The figures show large variations in cost of leverage and price as we vary $\gamma$ and change the distribution of fundamentals. Further Figure 6 Panel $C$ shows the cumulative distribution of liabilities (the endogenous $G(\rho)$ function) and Figure 6 Panel D shows the (endogenous) cumulative distribution of prices.

As explained previously, there are two countervailing intuitions at play in this example. First, if we keep $\hat{s}$ fixed, an improvement in fundamentals (higher $\gamma$ ) leads to lower face values for debt and hence lower endogenous liabilities (this is apparent from traveling vertically in Figure 6 Panel A for any shortfall $s$ ). The lower liabilities imply lower liquidations by any given firm and this tends to result in higher prices state by state (any realized value of $\theta_{2}$ ). However, as fundamentals improve, the pool of firms financed at date 0 expands. In particular, the threshold $\hat{s}$ below which firms are financed moves to the right on the x-axis, as can be seen by traveling horizontally in Figure 6 Panel A. This means that more levered firms enter the financial sector when expected

\footnotetext{
${ }^{13}$ Here $\theta_{\min }=0.3732$ using the restriction in Equation (13) and $\theta_{\max }=0.9$.

${ }^{14}$ Hopenhayn (1992) refers to this as monotone conditional dominance or MCD.
} 
fundamentals are better. In other words, for low realizations of fundamentals $\left(\theta_{2}\right)$, while each firm de-leverages less, there are more firms that need to de-lever, there is greater economy-wide distress and this pushes the market-clearing prices lower, as is apparent by traveling vertically in Figure 6 Panel B.

Consequently, an improvement in the expected distribution of fundamentals results in worse prices when financial distress materializes. This can be seen in Figure 6 Panel $\mathrm{C}$ which shows a higher cumulative distribution of liabilities $(\rho(s))$ when expectations for the future are better (higher $\gamma$ ). However, note that in an ex-ante sense, the probability of reaching financial distress states is much lower with better expected distribution of fundamentals. Figure 6 Panel D illustrates this by showing the cumulative distribution function of prices $p(\theta)$ under the two distributions. Hence, in expectation prices are still higher, which is precisely why $\hat{s}$ is higher in Figure 6 Panel $\mathrm{A}$ and higher leverage is sustained at date 0.

This example makes it clear that good expectations about the future enable even low-capital institutions to be funded ex ante and the resulting distribution of leverage in the economy can potentially lead to (il)liquidity effects in prices that are worse during crises that follow good times. Put another way, downside risk or negative skewness of future prices can be higher when adverse shocks arise in good times.

This outcome seems to have accompanied the phenomenon of Great Moderation in developed economies. A sectoral downward shift in volatility (Figure 2 Panel B) over the past two decades appeared to have led to cheap leverage (Figure 1 Panels A and B). This, in turn, gave rise to entry of relatively low-capital institutions in the financial sector in the form of structured purpose vehicles such as ABCP conduits and SIVs (Acharya, Schnabl and Suarez, 2009) and rapid asset growth of broker-dealers (Adrian and Shin, 2008). Accompanying this entry was substantial growth in ownership of assets related to residential and commercial real estate in these economies. When a severe aggregate shock hit the quality of these assets in the form of housing sector meltdown, de-leveraging and asset sales by highly levered financial institutions, again notably $A B C P$ conduits and broker-dealers, ensued. The relatively healthier institutions such as commercial banks with lower leverage also possessed little funding liquidity given the deterioration of the real estate assets they held. As a result, prices of real estate related assets seemed far lower than would be expected (Figure 2 Panel A) from a crisis that starts from relatively benign conditions.

It is useful to ask when the effect of endogenous entry at date 0 is likely to produce this counterintuitive phenomenon. Clearly, if the entry effect is weak, then prices can be higher state by state at date 1 when the distribution of fundamentals at date 0 is better. To see this possibility, we repeat the example above with a different distribution for financing shortfalls at date 0 :

$$
R(s)=1-\left(1-\frac{s-0.2}{t}\right)^{1 / \zeta},
$$


with $\zeta=0.05$. Our first example, the uniform distribution, corresponds to $\zeta=1$ in this new set-up. A higher $\zeta$ implies lower capital levels and more borrowing at date 0 in a FOSD sense. The distribution with $\zeta=0.05$ has a much thinner density in the right tail compared to the uniform distribution, implying that there are not many low-capital firms waiting at the fringe of the financial sector to enter. This reduces the endogenous entry effect.

Figure 7 Panels $A$ and $B$ show the relevant equilibrium outcomes for this example. In Figure 7 Panel A, we see again that $\rho(s)$ is lower when we move to better fundamentals and that $\hat{s}$ is higher. This effect that debt is cheaper in good times is the same as before. But now in Figure 7 Panel B, we see that state-by-state $(\theta)$, it is the low fundamentals case $(\gamma=0.5)$ that has the lower price (though the difference is quite small). Here the entry effect, measured as the change in $\hat{s}$, is muted because of the thinness of the right tail in the distribution of borrowing amounts. Figure 7 Panel $\mathrm{C}$ shows that the endogenous distribution of liabilities $G(\rho)$ is higher in a FOSD sense for the lower fundamentals case. This explains why prices are lower state by state for weaker fundamentals. Finally, Figure 7 Panel $D$ shows that higher fundamentals lead to higher expected prices as before.

To summarize, factors that enable low-capital institutions to enter the financial sector in good economic times (for example, the abundant flow of liquidity into the financial sector due to global imbalances (Bernanke, 2005)) also contribute to build-up of leverage in good times and the consequent effects of de-leveraging and deeply discounted prices when crises materialize. We note that we found it rather hard to construct the second example in that the right tail of the borrowing distribution had to be thinned considerably. We conjecture that our first example is important and robust. Indeed, it seems reasonable that high expectations lead to more leveraged players being financed. The endogenous capital structure of financial intermediaries over the business cycle is thus crucial to understanding severity of financial crises. ${ }^{15}$

\subsection{Optimality of debt contracts with lender control}

A key aspect of our model has been the use of short-term debt contracts, which if not rolled over lead to asset liquidations. Alternately, these contracts can be viewed as long-term debt contracts where lenders have interim control rights. In particular, the lender makes a two-period loan but

\footnotetext{
${ }^{15}$ In our model, there is no ex-post inefficiency from asset sales and transfers. This is purely for ease of exposition. Such inefficiencies arise in practice due to a variety of reasons such as asset mis-allocation, downward spirals relating to marking-to-market, and excess volatility (which would be welfare-relevant with risk-averse investors). Then, the greater severity of financial crises arising in good times creates a rationale for capital adequacy requirements. Interestingly, the primary role of such requirements would be to exclude the entry of poorly capitalized financial intermediaries and thereby reduce the extent of de-leveraging when adverse shocks materialize. Further, since leverage build-up is greater in good times, optimal requirements would have to bind in good times, lending them a counter-cyclical property.
} 
can call the loan at time 1 based on an observable signal of asset quality, inducing the firm to raise external finance or sell assets. This seems to correspond well to the nature of short-term rollover debt such as commercial paper or margins and collateral requirements in financial contracts. We argue in this subsection that in a model of incomplete contracts that follows Aghion and Bolton (1992) (see also Hart and Moore (1994), Hart (1995) and Diamond and Rajan (2001)), the borrowing contract with lender control maximizes the ex-ante financing available to investors. ${ }^{16}$

Our proof consists of two steps. First, we show that debt is the optimal contract. Second, we show that borrower control at date 1 is dominated by lender control at date 1 .

Consider any particular realization of asset quality $\theta_{2}$ at date 1 . Suppose for simplicity that accordance of control rights is equivalent to the controlling party making a take-it-or-leave-it offer at date 1. Intuitively, in absence of lender control, the borrower can always invoke the risk-shifting problem, that is, threaten to switch to the riskier asset and strategically renegotiate the lender down to $\rho^{*}\left(\theta_{2}\right)$. This would lower the payoffs to lenders at date 1 . In contrast, with lender control, the maximum amount available to lenders by threatening to force asset sales is $p^{*}\left(\theta_{2}\right) \geq \rho^{*}\left(\theta_{2}\right)$. Hence, lender control yields higher payoffs to the lender ex post. Ex ante, it is thus in the borrower's interest to give control rights to the lender and raise as much debt financing as possible. ${ }^{17}$ We formalize this intuition next.

To prove our results, we make three assumptions in the spirit of Aghion and Bolton (1992) and Hart and Moore (1994).

Assumption C1: Courts can verify whether the state 0 occurs or whether $\left\{y_{1}, y_{2}\right\}$ occurs, however they cannot distinguish between states $\left\{y_{1}, y_{2}\right\}$.

This assumption essentially states that there is some coarseness in the enforcement ability of courts. While contracts can distinguish between low and high states, they cannot discriminate between different high states.

Assumption C2: While the interim state $\theta_{2}$ is observable, it is not contractible.

This assumption forces the contract designer to give control conditional on the state $\theta_{2}$ to either the lender or the borrower. We believe that this assumption is justifiable in the context of financial institutions, especially hedge funds and broker-dealers, as they have complex portfolio

\footnotetext{
${ }^{16}$ Diamond (2004) in his Presidential address also discusses why short-term debt may resolve incentive problems. He focuses on an environment where the collective action problem makes it hard to renegotiate short-term debt and leads to a run on the firm. This is better for the borrower in an ex-ante sense. Diamond and Rajan (2001) present a similar argument to Diamond (2004).

${ }^{17}$ Note that our model differs from the standard Aghion and Bolton (1992) model in that borrower's ability to invoke the moral hazard problem gives the borrower too much power ex post. The only way to limit this is to give the ex-post control rights to the lender.
} 
strategies with many illiquid positions: the prime broker and hedge fund, for instance, may agree on a valuation, but courts may find it difficult to verify this.

Assumption C3: Payments at date 1 (ex-post states) cannot be bigger than the maximum payoff in that state or smaller than 0 .

This is a limited liability assumption and precludes payments in excess of what is available.

These three assumptions yield the desired result that debt contracts with lender control are optimal. From Assumption $\mathrm{C} 1$, the optimal contract must be a pair $\left\{0, \rho_{i}\right\}$ that pays off the same amount whether states $y_{1}$ or $y_{2}$ occur (we do not formally prove this as it is standard).

Assumption C2 implies that we have to compare borrower control or lender control in every state. With borrower control, if $\theta_{2} \rho_{i} \leq \rho^{*}\left(\theta_{2}\right)$, the borrower will honor the contract. However, if $\theta_{2} \rho_{i}>\rho^{*}\left(\theta_{2}\right)$, then we explain below that the borrower will credibly threaten to switch to the bad project. Hence, the lender will renegotiate the claim from $\rho_{i}$ to $\left[\rho^{*}\left(\theta_{2}\right)\right] / \theta_{2}=f^{*}\left(\theta_{2}\right)$. Thus with borrower control, the lender gets $\max \left[\theta_{2} \rho_{i}, \rho^{*}\left(\theta_{2}\right)\right]$ at date 1 .

To complete the argument that borrower control will lead to a credible threat of risk-shifting, we have to show that if the borrower makes a take or leave it offer of $f^{*}\left(\theta_{2}\right)<\rho_{i}$ and the lender rejects (hence leaving the face value at $\rho_{i}$ ), the borrower will in fact risk shift. We show this formally in the Appendix. Clearly, the borrower will risk shift if the face value is $\rho_{i}$ and no asset sales occur since by construction $f^{*}\left(\theta_{2}\right)$ is the highest face value of debt for which riskshifting remains unattractive. We also need to consider whether the borrower would ever engage in asset sales. Assets sales are unattractive to the borrower as they provide value to the lender immediately and reduce the borrower's risk-shifting option. Consequently, the borrower will not engage in asset sales and instead risk-shift, i.e., this is a credible threat.

In contrast, with lender control, the lender can threaten the borrower with liquidation at market prices. Hence, in this case, the lender gets $\max \left[\theta_{2} \rho_{i}, p^{*}\left(\theta_{2}\right)\right]$, where $p^{*}\left(\theta_{2}\right) \geq \rho^{*}\left(\theta_{2}\right)$ with strict inequality in states with sufficiently high $\theta_{2}$. Thus, borrowing with control rights allocated to the lender always generates higher ex-post payoff to the lender and thus greater ex-ante borrowing capacity for the borrower. We state this as a formal result:

Proposition 5 Under assumptions (C1)-(C3), the optimal contract is debt and lender control always yields a greater region of financed firms than borrower control. Further the short term debt contract with lender control is renegotiation-proof.

Giving control to the lender is renegotiation proof because if the lender were to renegotiate the contract without asset sales, he must reduce the face value to $\rho^{*} / \theta_{2}$ which yields a lower value than the optimal lender-control strategy (which involves liquidation). Giving the borrower 
control at this stage is suboptimal as the borrower (for reasons argued above) will risk-shift for sure and hence the lender will be forced to renegotiate to a lower face value of $\rho^{*} / \theta_{2}$. In contrast under lender control, the lender either gets $\theta_{2} \rho_{i}$ back or liquidates (possibly partially) to obtain $p^{*} \geq \rho^{*}$. Consequently, lender control is renegotiation-proof.

Proposition 5 justifies the structure of financing contracts for trading intermediaries (margin financing, rollover debt, etc.) where the risk-shifting problem is most pertinent. These contracts give strong ex-post control to the lender but reduce the borrower's ability to choose among risky projects and renegotiate. Importantly, the Proposition also rationalizes the contract structure that we have employed in our preceding analysis.

\section{Related literature}

The idea that asset prices may contain liquidity discounts when potential buyers are financially constrained dates back to Williamson (1988) and Shleifer and Vishny (1992). ${ }^{18}$ Since then, fire sales have been employed in finance models regularly, most notably by Allen and Gale (1994, 1998) to examine the links between limited market participation, volatility, and fragility observed in banking and asset markets. At its roots, our model is closely linked to this literature on an industry equilibrium view of asset sales; this makes it clear that market prices depend on funding liquidity of potential buyers. More broadly, the overall approach and ambition of our paper in relating the distribution of liquidity needs in an economy to equilibrium outcomes is closest to the seminal paper of Holmstrom and Tirole (1998). However, there are important differences with both these sets of papers.

In Allen and Gale $(1994,1998)$, the liquidity shocks arise as preference shocks to depositors or investors as in Diamond and Dybvig (1983). In Holmstrom and Tirole (1998), the liquidity shocks arise as production shocks to firms' technologies. In either case, they are not endogenous outcomes. We derive liquidity needs as being determined in equilibrium by asset-liability mismatch of firms, where the level and distribution of liabilities in the economy is an outcome of model primitives such as the distribution of asset quality and moral hazard problems in the future. The liabilities become liquidity "shocks" in our model, in the sense that liabilities are known in advance, but they take the form of "hard" debt contracts, and asset quality is uncertain in the

\footnotetext{
${ }^{18}$ Empirically, the idea of fire sales has now found ample empirical evidence in a variety of different settings: in distressed sales of aircrafts in Pulvino (1998), in cash auctions in bankruptcies in Stromberg (2000), in creditor recoveries during industry-wide distress especially for industries with high asset-specificity in Acharya, Bharath and Srinivasan (2007), in equity markets when mutual funds engage in sales of similar stocks in Coval and Stafford (2006), and, finally, in an international setting where foreign direct investment increases during emerging market crises to acquire assets at steep discounts in the evidence by Krugman (1998), Aguiar and Gopinath (2005), and Acharya, Shin and Yorulmazer (2007).
} 
future. The optimality of hard debt contract in our model with control rights given to lenders in case of default mirrors the work of Aghion and Bolton (1992), Hart and Moore (1994), Hart (1995), and Diamond and Rajan (2001).

In our model, we derive limited funding liquidity as arising due to credit rationing caused by risk-shifting moral hazard. Our specific modeling approach is closely related to the earlier models in Stiglitz and Weiss (1981) and Diamond (1989, 1991). In contrast, Holmstrom and Tirole's model of limited funding liquidity is based on rent-seeking moral hazard which appears a more appropriate metaphor for agency problems affecting real or technological choices, whereas risk-substitution fits better financial investment choices (typically by highly levered institutions). ${ }^{19}$ Our primary goal is to consider the implications of endogenously derived funding liquidity of assets for market prices and equilibrium leverage of the financial sector.

Our work is also related to the seminal work of Kiyotaki and Moore (1997) on credit cycles. In Kiyotaki and Moore (1997) and Krishnamurthy (2003), the underlying asset cannot be pledged because of inalienable human capital. ${ }^{20}$ However, land can be pledged and has value both as a productive asset and as collateral. Caballero and Krishnamurthy (2001) employ a HolmstromTirole approach to liquidity shocks (these are exogenous) and allow firms to post collateral in a manner similar to Kiyotaki and Moore. In contrast, the underlying asset in our model can be pledged ("asset sale") but the pledgeable amount is endogenously determined by the risk-shifting problem and the equilibrium distribution of leverage; in turn this determines the asset demands from potential buyers. In this sense, our objectives can be considered as the financial markets counterpart to those of Bernanke and Gertler (1989) who considered the role of real collateral in ameliorating agency problems linked to real investments, and its implications for business cycle.

Our model also has implications for the recent work in finance linking market liquidity and funding liquidity due to Gromb and Vayanos (2002), Plantin and Shin (2006), Anshuman and Viswanathan (2006), Brunnermeier and Pedersen (2009), and Garleanu and Pedersen (2009). In Gromb and Vayanos (2002), agents can only borrow if each asset is separately and fully collateralized, i.e., borrowing is essentially riskless. In Brunnermeier and Pedersen (2009), there is a collateral requirement that limits funding liquidity and is essentially exogenous: a shock to prices (or volatility) leads to liquidity shocks, that, in turn, leads to liquidation by financial intermediaries who engage in risk management. Garleanu and Pedersen (2009) consider margin constraints on certain intermediaries and assets. These models do not explicitly consider why lenders engage in risk management and why collateral or margin requirements are imposed (even though they do recognize that agency problems must be at play). Plantin and Shin (2006)

\footnotetext{
${ }^{19}$ For instance, it is hard for an auto manufacturer to hide its risks and be doing bio-tech pursuits instead of its core business, but relatively easy for a hedge-fund manager or investment bank to hide its risks by speculating in opaque or illiquid financial assets.

${ }^{20}$ Krishnamurthy (2003) differs from Kiyotaki and Moore (1997) in that all contingent claims on aggregate variables are allowed subject to collateral constraints.
} 
consider a dynamic variant of this feedback effect focusing on application to the unwinding of carry trades and their precipitous effect on exchange rates. ${ }^{21}$ Anshuman and Viswanathan (2006) point out that the ability to renegotiate constraints can eliminate liquidity crises of the nature analyzed in these papers, unless some other frictions are present.

Our paper presents one such friction arising due to the ability of financial intermediaries to substitute risks, which limits their borrowing capacity. Bolton, Santos and Scheinkman (2008) consider adverse selection as the relevant friction that generates price discounts in asset liquidations and limits funding capacity. Both moral hazard and adverse selection are likely to be at play in practice. Hence, we view our work as complementary to that of Bolton et al (2008).

Finally, Lorenzoni (2008) considers a competitive model of intermediaries with rent-seeking moral hazard and shows that there can be excessive borrowing ex ante and excessive volatility ex post. Lorenzoni's focus is on the (in)efficiency of the competitive equilibrium due to the pecuniary externality of asset liquidations and on preventive policies to curb the credit bubble and improve welfare. In our model too, the pecuniary externality exists as each firm's liquidations lower asset prices, raise loss given default for lenders, and thus raise ex-ante cost of borrowing for all firms. We focus, however, on the positive implications for financial crises arising from a riskshifting problem faced by intermediaries rather than the normative implications of the rent-seeking problem considered by Lorenzoni. Footnote 15 discussed how such normative considerations could be introduced in our model to derive welfare implications.

\section{Concluding remarks}

In this paper, we presented a model of the financial sector in which short-term or rollover debt is an optimal contracting response to the manager's ability to risk-shift across assets. This riskshifting limits the manager's ability to raise new debt to roll over old short term debt and provides a microeconomic foundation for the linkage between market liquidity and funding liquidity. Building on this foundation, we derived a body of results that help understand the de-leveraging of the financial sector during crises, including the crisis of 2007-09. In particular, we showed that the extent of the funding liquidity problem and induced de-leveraging or fire sales faced by each financial firm is determined by the extent of its own short-term debt, the adversity of the asset shock, the specificity of assets to borrowers relative to lenders, and the amount of short-term debt with potential buyers of assets, i.e., other financial firms.

Our most surprising result was that since good economic times are associated with a low cost of short-term debt and in turn greater entry of highly-levered financial institutions, adverse asset

\footnotetext{
${ }^{21}$ Morris and Shin (2004) present a model where traders are liquidated when an exogenous trigger price is reached and this trigger is different for each trader.
} 
shocks that materialize after such times lead to greater de-leveraging and asset-price deterioration. While the incidence of financial crisis is lower when expectations of fundamentals are high, the severity of crisis that arise subsequently can be greater due to the greater system-wide leverage. Recognizing this crucial role played by the distribution of leverage in the financial sector - and its endogenous relationship to the business cycle - appears central to understanding crises.

\section{Appendix}

Proof of Proposition 2: We first prove that the market-clearing price $p^{*}$ exists and is unique.

Step 1. The demand function for assets is given by

$$
D\left(p, \rho^{*}\right)\left\{\begin{array}{cc}
=\int_{\rho_{\min }}^{\rho^{*}} \frac{\left(\rho^{*}-\rho\right)}{\left(p-\rho^{*}\right)} g(\rho) d \rho & \text { if } p<\bar{p} \\
\in\left[0, \int_{\rho_{\min }}^{\rho^{*}} \frac{\left(\rho^{*}-\rho\right)}{\left(p-\rho^{*}\right)} g(\rho) d \rho\right] & \text { if } p=\bar{p}
\end{array}\right.
$$

where at price $\bar{p}$, we get an interval of possible demand as buyers are indifferent between not buying and buying up to their maximum liquidity. Hence, the excess demand function is given by

$$
E\left(p, \rho^{*}\right)\left\{\begin{array}{cc}
=-1+\frac{1}{\left(p-\rho^{*}\right)} \int_{\rho_{\min }}^{p} G(\rho) d \rho & \text { if } p<\bar{p} \\
\in\left[-1+\frac{1}{\left(p-\rho^{*}\right)} \int_{\rho_{\min }}^{p} G(\rho) d \rho,-\int_{\rho^{*}}^{p} \frac{\left(\rho-\rho^{*}\right)}{\left(p-\rho^{*}\right)} g(\rho) d \rho-\int_{p}^{\rho_{\max }} g(\rho) d \rho\right] & \text { if } p=\bar{p}
\end{array}\right.
$$

where as before we get an interval at $\bar{p}$.

Step 2. Note that the excess demand for $p=\rho^{*}$ is positive infinity.

Step 3. If the excess demand is positive for all $p<\bar{p}$, the price must be $\bar{p}$, as at $\bar{p}$ the interval definition of excess demand above includes 0 . So, $\bar{p}$ is the only feasible price. Intuitively, if there are more agents willing to buy than sell at the highest possible price, this must be the price.

Step 4. If the excess demand is negative as $p \rightarrow \bar{p}$, we must have at least one solution for $p$. However, we note that for $\rho^{*}<p<\bar{p}$, the derivative of the excess demand (when the excess demand is $\geq 0$ ) is given by

$$
\frac{\partial E\left(p, \rho^{*}\right)}{\partial p}=-\frac{1}{\left(p-\rho^{*}\right)^{2}} \int_{\rho_{\min }}^{p} G(\rho) d \rho+\frac{G(p)}{p-\rho^{*}} \leq-\frac{1}{\left(p-\rho^{*}\right)}+\frac{G(p)}{p-\rho^{*}} \quad<0,
$$

where we use the fact that a positive excess demand implies that $\frac{1}{\left(p-\rho^{*}\right)} \int_{\rho_{\min }}^{p} G(\rho) d \rho \geq 1$ and that $G(p)<1$. Hence, when excess demand is zero, its derivative must also be negative, so we can only have one price that sets excess demand to zero and the price $\bar{p}$ is unique.

Step 5. To prove that $p^{*}$ is increasing in $\rho^{*}$, note that the excess demand function has a positive derivative with respect to $\rho^{*}$ for all $p<\bar{p}$ (as can be verified using the expression for 
excess demand in Step 1 above). Since the excess demand function is strictly downward sloping for positive excess demand, it immediately follows that $p^{*}$ is strictly increasing in $\rho^{*}$ if $p^{*}<\bar{p}$; otherwise the price just stays at $\bar{p}$.

Step 6. It follows from Step 5 that there exists a unique critical value $\hat{\rho}^{*} \in\left(\rho_{\min }, \bar{p}\right)$ such that the market-clearing price $p^{*}=\bar{p}, \forall \rho^{*} \geq \hat{\rho}^{*}$ and $p^{*}<\bar{p}$ otherwise, in which case $p^{*}$ satisfies equation (12). Note also from equation (12) that we must have $p^{*} \geq \rho^{*}$ with equality arising only when $\rho^{*}=\rho_{\min }$. This completes the proof.

Proof of Proposition 4: The fixed point problem of Section 3.1 can be solved as follows. Fix a maximal financing $\hat{s}$. First we invert (15) and solve for $\theta_{2}(p)$ : we show below that since this is an explicit quadratic equation, we can solve for this variable. We impose the constraint that price is at most $\theta_{2} y_{2}$. We can substitute $\theta_{2}(p)$ into the differential equation for $s(\rho),(19)$, to obtain an integro-differential equation that has a unique solution for $s(\rho)$. The maximum financing is then uniquely solved by the boundary condition in (17).

Given the cdf of amount financed, $R(s)$, the cdf of face values conditional on financing being over the truncated support of amounts financed $\left[\theta_{1} y_{1}, \hat{s}\right]$, is denoted as $\hat{G}(u)$, and is given by $\hat{G}(u)=\frac{R(s(u))}{R(\hat{s})}$, where $\hat{G}(u)=\operatorname{Prob}[\rho \leq u \mid s \leq \hat{s}]=\operatorname{Prob}[s(\rho) \leq s(u) \mid s \leq \hat{s}]$. Define

$$
L(p)=p-\int_{\theta_{1} y_{1}}^{p} \hat{G}(\rho) d \rho
$$

where we have switched back to $\rho$ as being the variable of integration.

Then, setting $L(p)=\rho^{*}\left(\theta_{2}\right)$ to satisfy (15) with equality, we obtain

$$
\theta_{2} \frac{\left(\theta_{2} y_{2}-\theta_{1} y_{1}\right)}{\left(\theta_{2}-\theta_{1}\right)}=L(p)
$$

which yields an explicit solution for $\theta_{2}$. Since prices cannot be above $\theta_{2} y_{2}$ (hence $\theta_{2} \geq \frac{p}{y_{2}}$ ), we obtain the following solution for $\theta_{2}(p)$

$$
\theta_{2}(p)=\max \left\{\frac{\left(\theta_{1} y_{1}+L(p)\right)+\sqrt{\left(\theta_{1} y_{1}+L(p)\right)^{2}-4 y_{2} L(p) \theta_{1}}}{2 y_{2}}, \frac{p}{y_{2}}\right\}
$$

on the domain $\left[\theta_{1} y_{1}, \theta_{\max } y_{2}\right]$. Note that this equation defines $\theta_{2}(p)$ in terms of $s(\rho)$ since $L(p)$ depends on the function $\hat{G}(\rho)=\frac{R(s(\rho))}{R(\hat{s})} \cdot{ }^{22}$

\footnotetext{
${ }^{22}$ Note that if $p=\theta_{1} y_{1}$, then equation (29) is determined by the first expression in the max operator and $\theta_{2}(p)$ $=\theta_{\min }$ as $L\left(\theta_{1} y_{1}\right)=\theta_{1} y_{1}$. At the other end point, $p=\theta_{\max } y_{2}$, either we have $\theta_{2}\left(\theta_{\max } y_{2}\right)=\theta_{\max }$, and there is no price discount at $\theta_{\max }$; or $\theta_{2}\left(\theta_{\max } y_{2}\right)>\theta_{\max }$ and there is a price discount in every state.
} 
Next, we solve the differential equation implied by (19) (which is itself equivalent to (16)):

$$
\frac{d s}{d \rho}=1-H\left(\theta_{2}(\rho)\right)
$$

where $H\left(\theta_{2}\right)$ is the cdf of $\theta_{2}$. Since it is possible that $\theta_{2}(p)>\theta_{\max }$ in (30), we extend $H\left(\theta_{2}\right)$ by assuming that $H\left(\theta_{2}\right)=1$ for $\theta_{2}>\theta_{\max }$ (this is true and innocuous since $1-H\left(\theta_{2}\right)=0$ for such $\left.\theta_{2}\right)$. Then, substituting for $\theta_{2}(p)$ from (29), we obtain that

$$
\frac{d s}{d \rho}=1-H\left(\max \left\{\frac{\left(\theta_{1} y_{1}+L(\rho)\right)+\sqrt{\left(\theta_{1} y_{1}+L(\rho)\right)^{2}-4 y_{2} L(\rho) \theta_{1}}}{2 y_{2}}, \frac{\rho}{y_{2}}\right\}\right)
$$

with the end-point constraint that $s\left(\theta_{1} y_{1}\right)=\theta_{1} y_{1}$.

This is a standard integro-differential equation of the form

$$
\frac{d s}{d \rho}=f\left(\rho, \int_{\theta_{1} y_{1}}^{\rho} \frac{R(s(u))}{R(\hat{s})} d u\right)
$$

with the end-point constraint $s\left(\theta_{1} y_{1}\right)=\theta_{1} y_{1}$, and it has a unique solution if the function $f(\rho, t)$ is Lipschitz in $t$ and the function $R(s)$ is Lipschitz in $s$ (as we show below).

We now solve for the maximal financing $\hat{s}$, which is given by the condition

$$
\hat{s} \leq \int_{\theta_{\min }}^{\theta_{\max }} p\left(\theta_{2}\right) h\left(\theta_{2}\right) d \theta_{2}
$$

where $p\left(\theta_{2}\right)$ is the inverse function of $\theta_{2}(p)$ and $h\left(\theta_{2}\right)$ is the density of $\theta_{2}$.

The left hand side of (33) is $\theta_{1} y_{1}$ at $\hat{s}=\theta_{1} y_{1}$ and increasing in $\hat{s}$. The right hand side of (33) is strictly greater than $\theta_{1} y_{1}$ at $\hat{s}=\theta_{1} y_{1}$ and decreasing in $\hat{s}^{23}$ Either (33) has a unique solution or no solution with strict inequality at $\hat{s}$, in that case there is no exclusion and $\hat{s}=s_{\max }$.

This completes the proof of proposition, save the technical detail below.

Existence and uniqueness of solution to the fixed-point problem: Granas and Dugundji (2003), Theorem 2.1, shows a general approach to existence of Volterra integral equations of the second kind. We adapt their proof to our set up.

We first show that if $f(\rho, t)$ is Lipschitz in $t$ with Lipschitz constant $L_{1}$ and $R(s)$ is Lipschitz in $s$ with Lipschitz constant $L_{2}$, we can prove existence and uniqueness, at the end of the proof

\footnotetext{
${ }^{23}$ To see this note that if we increase $\hat{s}$, we decrease $\hat{G}(\rho)$, which means we increase $L(p)$ and hence $\theta_{2}(p)$; therefore $p\left(\theta_{2}\right)$ decreases, and, in turn, the right hand side of the (33) decreases.
} 
we provide sufficient conditions of the Lipschitz continuity of these functions. Here the function $R(s)$ is the cdf of initial borrowing and $f(\rho, t)$ is the function implicitly defined in Equations (31) and (32).

Let $L=\max \left\{L_{1}, \frac{L_{2}}{R(\hat{s})}\right\}$. Let $\mathbf{E}$ be the Banach space of all continuous real valued function on $\left[\theta_{1} y_{1}, \theta_{\max } y_{2}\right]$ equipped with the norm

$$
\|s\|=\max _{\theta_{1} y_{1} \leq \rho \leq \theta_{\max } y_{2}} e^{-L \rho}|s(\rho)|
$$

This norm is equivalent to the standard sup norm $\|x\|_{s}$ (a function Lipschitzian in one norm is Lipschitzian in any equivalent norm) because

$$
e^{-L \theta_{\max } y_{2}}|| x\left\|_{s} \leq\right\| x\|\leq\| x \|_{s} .
$$

Further, the norm is complete.

Define $M(s)(\rho)=\int_{\theta_{1} y_{1}}^{\rho} \frac{R(s(u))}{R(\hat{s})} d u$ where $s$ refers to the function $s(\rho)$ on $\left[\theta_{1} y_{1}, \theta_{\max } y_{2}\right]$. We first note that

$$
\begin{aligned}
& \left\|M\left(s^{\prime}\right)-M(s)\right\| \\
\leq & \max _{\theta_{1} y_{1} \leq \rho \leq \theta_{\max } y_{2}} e^{-L \rho} \int_{\theta_{1} y_{1}}^{\rho}\left|\frac{R\left(s^{\prime}(u)\right.}{R(\hat{s})}-\frac{R(s(u)}{R(\hat{s})}\right| d u \\
\leq & \frac{L_{1}}{R(\hat{s})} \max _{\theta_{1} y_{1} \leq \rho \leq \theta_{\max } y_{2}} e^{-L \rho} \int_{\theta_{1} y_{1}}^{\rho}\left|s^{\prime}(u)-s(u)\right| d u \\
\leq & L \max _{\theta_{1} y_{1} \leq \rho \leq \theta_{\max } y_{2}} e^{-L \rho} \int_{\theta_{1} y_{1}}^{\rho}\left|s^{\prime}(u)-s(u)\right| d u \\
\leq & L \max _{\theta_{1} y_{1} \leq \rho \leq \theta_{\max } y_{2}} e^{-L \rho} \int_{\theta_{1} y_{1}}^{\rho} e^{L u} e^{-L u}\left|s^{\prime}(u)-s(u)\right| d u \\
\leq & L\left\|s^{\prime}-s\right\| \max _{\theta_{1} y_{1} \leq \rho \leq \theta_{\max } y_{2}} e^{-L \rho} \int_{\theta_{1} y_{1}}^{\rho} e^{L u} d u \\
= & L\left\|s^{\prime}-s\right\| \max _{\theta_{1} y_{1} \leq \rho \leq \theta_{\max } y_{2}} e^{-L \rho} \frac{e^{L \rho}-e^{L \theta_{1} y_{1}}}{L} \\
\leq & \left(1-e^{-L\left(\theta_{\max } y_{2}-\theta_{1} y_{1}\right)}\right)\left\|s^{\prime}-s\right\|
\end{aligned}
$$

Next define the map F:E $\rightarrow \mathbf{E}$ by

$$
F(s)(\rho)=\int_{\theta_{1} y_{1}}^{\rho} f(t, M(s)(t)) d t
$$


where $s$ is the function $s(\rho)$. We wish to show this is a contractive map, hence

$$
\begin{aligned}
& \left\|F\left(s^{\prime}\right)-F(s)\right\| \\
\leq & \max _{\theta_{1} y_{1} \leq \rho \leq \theta_{\max } y_{2}} e^{-L \rho} \int_{\theta_{1} y_{1}}^{\rho} \mid f\left(t, M\left(s^{\prime}\right)(t)-f(t, M(s)(t) \mid d t\right. \\
\leq & L \max _{\theta_{1} y_{1} \leq \rho \leq \theta_{\max } y_{2}} e^{-L \rho} \int_{\theta_{1} y_{1}}^{\rho}\left|M\left(s^{\prime}\right)(t)-M(s)(t)\right| d t \\
\leq & \left.L\left\|M\left(s^{\prime}\right)-M(s)\right\|\right|_{\theta_{1} y_{1} \leq \rho \leq \theta_{\max } y_{2}} e^{-L \rho} \int_{\theta_{1} y_{1}}^{\rho} e^{L t} d t \\
\leq & L\left\|M\left(s^{\prime}\right)-M(s)\right\| \max _{\theta_{1} y_{1} \leq \rho \leq \theta_{\max } y_{2}} e^{-L \rho} \frac{e^{L \rho}-e^{L \theta_{1} y_{1}}}{L} \\
\leq & \left(1-e^{-L\left(\theta_{\max } y_{2}-\theta_{1} y_{1}\right)}\right) \quad\left\|M\left(s^{\prime}\right)-M(s)\right\| \\
\leq & \left(1-e^{-L\left(\theta_{\max } y_{2}-\theta_{1} y_{1}\right)}\right)^{2} \quad\left\|s^{\prime}-s\right\|
\end{aligned}
$$

which is contractive as $\left(1-e^{-L\left(\theta_{\max } y_{2}-\theta_{1} y_{1}\right)}\right)<1$. Hence, by the Banach contraction theorem, we have a unique fixed point in $\mathbf{E}$ and the sequence given by successive iterations $F^{n}(s)$ converges to this unique fixed point uniformly in the norm $\|\cdot\|$ and hence in the standard sup norm $\|\cdot\|_{s}$.

We now fill in the details of Lipschitz continuity. We know that if an arbitrary function $f$ is differentiable with bounded derivative $f^{\prime}(\rho) \leq L$, then $f$ is Lipschitz with constant $K<L$. Thus, it suffices for the cdf $R(s)$ to assume that it has bounded derivative over the interval $\left[\theta_{1} y_{1}, \theta_{\max } y_{2}\right]$.

To prove that the function $f(\rho, t)$ defined by

$$
f(\rho, t)=1-H\left(\max \left\{\frac{\left(\theta_{1} y_{1}+(\rho-t)\right)+\sqrt{\left(\theta_{1} y_{1}+(\rho-t)\right)^{2}-4 y_{2}(\rho-t) \theta_{1}}}{2 y_{2}}, \frac{\rho}{y_{2}}\right\}\right)
$$

is Lipschitz in $\rho$, define the auxiliary function

$$
\hat{f}(\rho, t)=1-H\left(\frac{\left(\theta_{1} y_{1}+(\rho-t)\right)+\sqrt{\left(\theta_{1} y_{1}+(\rho-t)\right)^{2}-4 y_{2}(\rho-t) \theta_{1}}}{2 y_{2}}\right)
$$

which is Lipschitz is $\rho$ provided the $\operatorname{cdf} H(\cdot)$ is differentiable with bounded derivatives. But this suffices for function $f$. Given $\rho$, let $\hat{t}(\rho)$ be the point where the two terms in the maximum function are equal (the function is not differentiable at this point in $t$ ). If $t, t^{\prime} \geq \hat{t}(\rho)$ ), the Lipschitz continuity of $\hat{f}(\rho, t)$ in $t$ suffices. If $t>\hat{t}(\rho)>t^{\prime}$ we note that $\left|f(\rho, t)-f\left(\rho, t^{\prime}\right)\right|=$ $|f(\rho, t)-f(\rho, \hat{t}(\rho))|$ and we can use the Lipschitz continuity of $\hat{f}(\rho, t)$ in $\mathrm{t}$ as follows:

$$
\left|f(\rho, t)-f\left(\rho, t^{\prime}\right)\right|=|f(\rho, t)-f(\rho, \hat{t}(\rho))|=|\hat{f}(\rho, t)-\hat{f}(\rho, \hat{t}(\rho))|=L_{1}|\hat{t}(\rho)-t| \leq L_{1}\left|t^{\prime}-t\right|
$$


which completes the proof of Lipschitz continuity of the function $f(\rho, t)$ in $t$.

Solving the integro-differential equation: Finally, we discuss the numerical method used to solve the integro-differential equation,

$$
\frac{d s}{d \rho}=1-H\left(\max \left\{\frac{\left(\theta_{1} y_{1}+L(\rho)\right)+\sqrt{\left(\theta_{1} y_{1}+L(\rho)\right)^{2}-4 y_{2} L(\rho) \theta_{1}}}{2 y_{2}}, \frac{\rho}{y_{2}}\right\}\right)
$$

with the end point constraint that $s\left(\theta_{1} y_{1}\right)=\theta_{1} y_{1}$.

We find the initial value of $\hat{s}$ on $\left[\theta_{1} y_{1}, \theta_{\max } y_{2}\right]$ as follows:

$$
\hat{s}=\int_{\theta_{\min }}^{\theta_{\max }} \theta_{2} y_{2} h\left(\theta_{2}\right) d \theta_{2}
$$

where we have used the fact that $\theta_{2} y_{2}$ is the highest possible price in each state.

Then, the recursive algorithm works as follows. We start with $s(\rho)=\rho$ on $\left[\theta_{1} y_{1}, \theta_{\max } y_{2}\right]$ and use this to derive a first order Riemann sum numerical approximation to the integral on a discrete grid $\left[t_{0}=\theta_{1} y_{1}, t_{1}, \ldots, t_{N}=\theta_{\max } y_{2}\right]$ as

$$
\int_{\theta_{1} y_{1}}^{t_{n}} \hat{G}(\rho) d \rho=\sum_{k=1}^{n}\left(t_{k}-t_{k-1}\right) \hat{G}\left(t_{k-1}\right)
$$

For each $t_{n}$,

$$
L\left(t_{n}\right)=t_{n}-\sum_{k=1}^{n}\left(t_{k}-t_{k-1}\right) \hat{G}\left(t_{k-1}\right)
$$

The integro-differential equation is then approximated by the first order Taylor expansion

$$
\begin{gathered}
s\left(t_{n+1}\right) \\
=s_{n}+\left(t_{n+1}-t_{n}\right)\left(1-H\left(\max \left\{\frac{\left(\theta_{1} y_{1}+L\left(t_{n}\right)\right)+\sqrt{\left(\theta_{1} y_{1}+L\left(t_{n}\right)\right)^{2}-4 y_{2} L\left(t_{n}\right) \theta_{1}}}{2 y_{2}}, \frac{t_{n}}{y_{2}}\right\}\right)\right)
\end{gathered}
$$

This yields a new grid approximation $s\left(t_{n}\right)$. Next, we set the value of $\hat{s}$ as $s\left(t_{N}\right)$ and repeat the above process until convergence occurs (maximum difference in $s\left(t_{n}\right)$ is 0.001 ). This ensures that $\hat{s}$ also converges.

\section{Proof of Proposition 5:}


We provide the details of the credibility of the borrower's threat to risk-shift when he has control. Suppose the borrow threatens to risk shift and offers the lender a new face value of $\rho^{*} / \theta_{2}$ where $\theta_{2} \rho_{i}>\rho^{*}$. We need to show that when the lender rejects this offer and keeps the face value at $\rho_{i}$, the borrower will risk shift, i.e., the threat is credible. In particular, we have to show that it is not optimal for the borrower to engage in any asset sales. If the borrower does not engage in asset sales, he will risk-shift since $\rho_{i}>\rho^{*} / \theta_{2}$ and hence the borrower will obtain in expectation $\theta_{1}\left(y_{1}-\rho_{i}\right)$.

If the borrower sells assets of fraction $\alpha$, he will obtain a price $p \leq \theta_{2} y_{2}$ for these assets. Clearly, he will not sell the whole firm since $\theta_{1}\left(y_{1}-\rho_{i}\right)>\theta_{2}\left(y_{2}-\rho_{i}\right)>\theta_{2} y_{2}-\rho_{i} \geq p-\rho_{i}$, i.e., it is not optimal to pay the face value today given the value of the option to risk shift. Generalizing this, if the lender sells a fraction $\alpha$ and pays $\alpha p$ to the lender, his remaining loan amount is given by $(1-\alpha) \hat{\rho}_{i}=\rho_{i}-\alpha p$. If $\hat{\rho}_{i}>\rho^{*} / \theta_{2}$, the lender will risk shift and we know that

$$
\begin{aligned}
& \theta_{1}\left[(1-\alpha)\left(y_{1}-\hat{\rho}_{i}\right)\right] \\
< & \theta_{1}\left[(1-\alpha)\left(y_{1}-\hat{\rho}_{i}\right)\right]+\theta_{1}\left[\alpha\left(y_{1}-p\right)\right] \\
= & \theta_{1}\left(y_{1}-\rho_{i}\right) .
\end{aligned}
$$

Hence, the borrower will not sell assets and then risk shift, i.e., asset sales are not optimal for the borrower when he risk shifts.

The last possibility is that the borrower sells just enough assets so as not to risk shift, i.e., $\hat{\rho}_{i}$ $=\rho^{*} / \theta_{2}$. In this case, we obtain similarly that

$$
\begin{aligned}
& \theta_{2}\left[(1-\alpha)\left(y_{2}-\hat{\rho}_{i}\right)\right] \\
= & \theta_{1}\left[(1-\alpha)\left(y_{1}-\hat{\rho}_{i}\right)\right] \\
< & \theta_{1}\left[(1-\alpha)\left(y_{1}-\hat{\rho}_{i}\right)\right]+\theta_{1}\left[\alpha\left(y_{1}-p\right)\right] \\
= & \theta_{1}\left(y_{1}-\rho_{i}\right)
\end{aligned}
$$

where we have used the indifference to risk shifting in the first equality.

Intuitively, it is not optimal for the borrower to conduct asset sales and not to risk shift as this only helps the lender. Asset sales reduce the value of the risk-shifting option and give the lender the money one-period early, which cannot be optimal for the borrower ex post.

The second aspect of the proof that we complete here is that lender control is renegotiationproof. In any renegotiation, the lender has to reduce the lending to $\rho^{*}$ as otherwise risk-shifting occurs. Given that the lender cannot distinguish between $\left\{y_{1}, y_{2}\right\}$ and he cannot ask for more than 0 in the low state, the optimal contract must be debt. Consequently, if he is to get more than $\rho^{*}$ in value, he has to force asset sales. We have already seen that the borrower will never engage in asset sales, so the lender cannot give control to him. Hence, no renegotiation is possible at 
date 1 , i.e., lender control is optimal, lenders do not renegotiate at date 1 , and forced liquidations will occur in equilibrium.

\section{References}

Acharya, Viral, Sreedhar Bharath and Anand Srinivasan (2007). "Does Industry-wide Distress Affect Defaulted Firms? - Evidence from Creditor Recoveries," Journal of Financial Economics, 85(3), 787-821.

Acharya, Viral, Thomas Philippon, Matthew Richardson and Nouriel Roubini (2009), "Prologue: A Bird's Eye View," in Acharya, Viral and Matthew Richardson, eds., Restoring Financial Stability, New York University and John Wiley \& Sons.

Acharya, Viral, Philipp Schnabl and Gustavo Suarez (2009). "Securitization Without Risk Transfer," Working Paper, New York University Stern School of Business.

Acharya, Viral V., Hyun-Song Shin and Tanju Yorulmazer (2007). "Fire-sale FDI," Working Paper, New York University Stern School of Business.

Adrian, Tobias and Hyun-Song Shin (2008). "Liquidity and Leverage," Journal of Financial Intermediation, forthcoming.

Aghion, P. and P. Bolton (1992). "An Incomplete Contracts Approach to Contracting," The Review of Economic Studies, 59(3), 473-494.

Aguiar, Mark and Gita Gopinath (2005). "Fire-Sale FDI and Liquidity Crises," The Review of Economics and Statistics, 87(3), 439-542.

Allen, Franklin and Douglas Gale (1994). "Liquidity Preference, Market Participation and Asset Price Volatility," American Economic Review, 84, 933-955.

Allen, Franklin and Douglas Gale (1998). "Optimal Financial Crises, Journal of Finance, 53, 1245-1284.

Anshuman, Ravi and S. Viswanathan, 2006, "Collateral and Market Liquidity," Working Paper, Fuqua School of Business, Duke University.

Bernanke, Ben, 2005, "The Global Saving Glut and the U.S. Current Account Deficit," speech delivered for the Sandridge Lecture at the Virginia Association of Economists, Richmond, March 10, www.federalreserve.gov/boarddocs/speeches/2005/200503102/default.htm. 
Bernanke, Ben and Mark Gertler, 1989, "Agency Costs, Net Worth, and Business Fluctuations," American Economic Review, 79(1), 14-31.

Bolton, Patrick, Tano Santos and Jose Scheinkman, 2008. "Inside and Outside Liquidity," Working Paper, Columbia University.

Brunnermeier, Markus and Lasse H. Pedersen (2009). "Market Liquidity and Funding Liquidity," Review of Financial Studies, 22, 2201-2238.

Caballero R. and A. Krishnamurthy, 2001, "International and Domestic Collateral Constraints in a model of Emerging Market Crisis," Journal of Monetary Economics, 48(3), 513-548.

Coval, Joshua and Erik Stafford (2006) "Asset Fire Sales in Equity Markets, Journal of Financial Economics, forthcoming.

Diamond, Douglas (1989). "Reputation Acquisition in Debt Markets, " Journal of Political Economy, 97 (4), 828-862.

Diamond, Douglas (1991). "Debt Maturity Structure and Liquidity Risk, " Quarterly Journal of Economics, 106 (3),709-737.

Diamond, Douglas (2004). "Presidential Address: Committing to Commit: Short Term Debt When Enforcement is Costly, " Journal of Finance, 59 (4), 1447-1479.

Diamond, Douglas and Dybvig, Philip (1983). "Bank Runs, Deposit Insurance, and Liquidity," Journal of Political Economy, 91(3), 401-19.

Douglas W. Diamond and Raghuram G. Rajan (2001). "Liquidity Risk, Liquidity Creation, and Financial Fragility: A Theory of Banking," Journal of Political Economy, 109(2), 287-327.

Garleanu, Nicolae and Lasse Pedersen (2009). "Margin-Based Asset Pricing and Deviations from the Law of One Price," Working Paper, NYU-Stern.

Granas, Andrej and James Dugundji. (2003). Fixed Point Theory, Springer Monographs in Mathematics, Springer-Verlag, New York.

Gromb, Denis and Dimitri Vayanos (2002). "Equilibrium and Welfare in Markets with Financially Constrained Arbitrageurs," Journal of Financial Economics, 66, 361-407.

Hart, O. and J. Moore, (1994). "A Theory of Debt Based on the Inalienability of Human Capital," Quarterly Journal of Economics, 109(4), 841-79.

Hart, O, "Firms, Contracts and Financial Structure," Oxford: Oxford University Press (1995). 
Holmstrom, Bengt and Jean Tirole (1998). "Private and Public Supply of Liquidity," Journal of Political Economy, 106, 1-14.

Hopenhayn, H.A., 1992, "Entry, Exit, and firm Dynamics in Long Run Equilibrium," Econometrica, 60(5), 1127-1150.

Jensen, M., and W. Meckling (1976). "Theory of the Firm: Managerial Behavior, Agency Costs, and Capital Structure," Journal of Financial Economics, 3, 305-360.

Kiyotaki, N. and J. Moore, (1997). "Credit Cycles," Journal of Political Economy, 105(2), 211-248.

Krishnamurthy, A. (2003) "Collateral Constraints and the Amplification Mechanism," Journal of Economic Theory, 111(2), 277-292.

Krugman, Paul (1998). "Fire-sale FDI," available at http://web.mit.edu/krugman/www/FIRESALE.htm.

Lorenzoni, G. (2008) "Inefficient Credit Booms," Review of Economic Studies, 75(3), 809-833.

Morris, S. and H-S. Shin (2004), "Liquidity Black Holes," Review of Finance, 8, 1-18.

Plantin, Guillaume and Hyun-Song Shin (2006). "Carry Trades and Speculative Dynamics," Working paper, London Business School.

Pulvino, Todd C. (1998) "Do Asset Fire Sales Exist: An Empirical Investigation of Commercial Aircraft Sale Transactions," Journal of Finance, 53, 939-978.

Shleifer, Andrei and Robert Vishny (1992). "Liquidation values and debt capacity: A market equilibrium approach," Journal of Finance, 47, 1343-1366.

Stiglitz, Joseph and Weiss, A. (1981). "Credit Rationing in Markets with Imperfect Information," American Economic Review, 71, 393-410.

Stock, J.H. and M.W. Watson. (2002) "Has the Business Cycle Changed and Why?" NBER Macroeconomics Annual, 159-218.

Williamson, Oliver E. (1988). "Corporate Finance and Corporate Governance," Journal of Finance, 43, 567-592. 
Figure 1: Panel A shows the behavior of asset-backed commercial paper (ABCP) spread over the Federal funds rate during 2007 (Source: Federal Reserve Board). Panel B shows the outstanding amounts of asset-backed commercial (ABCP) paper during 2004-2009 (Source: Quarterly data reports from Moody's Investor Services).

Panel A: The behavior of asset-backed commercial paper ( $A B C P)$ spread over the Federal funds rate during 2007 (Source: Federal Reserve Board)

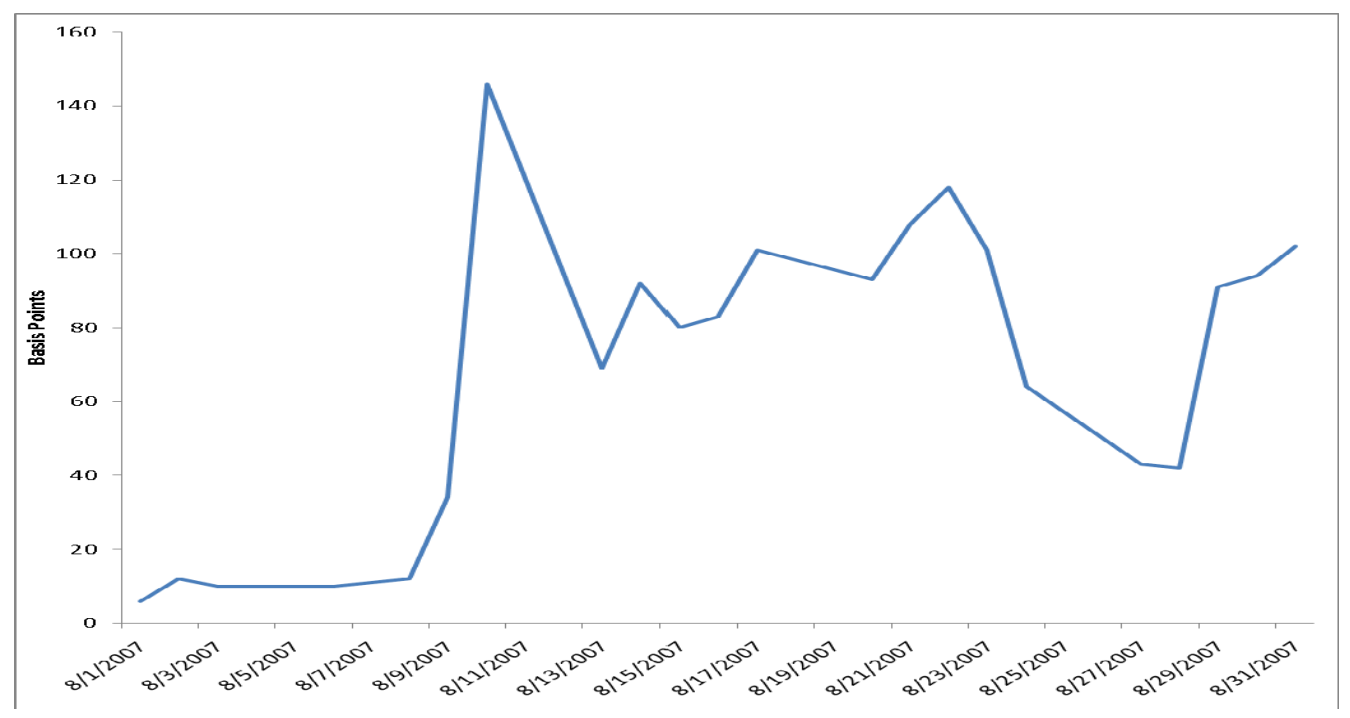

Panel B: Outstanding amounts of asset-backed commercial (ABCP) paper during 2004-2009

(Source: Quarterly data reports from Moody's Investor Services)

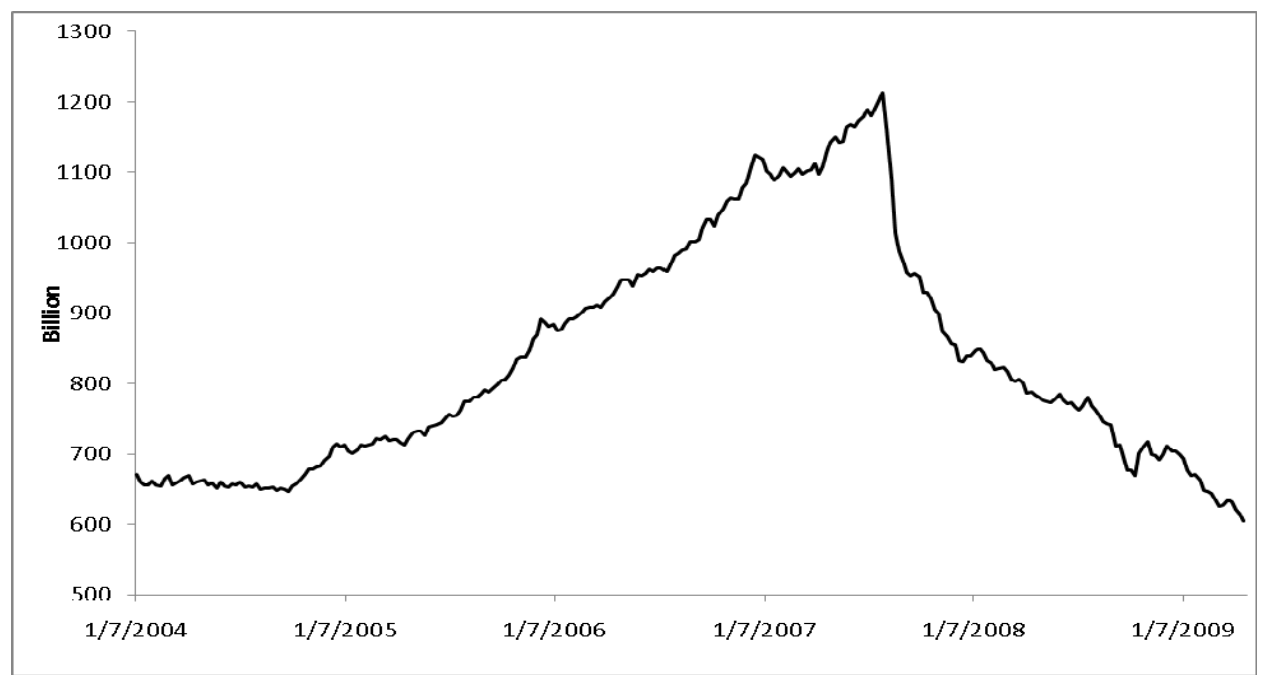


Figure 2: Panel A shows the behavior of VIX, the option-implied measure of volatility during 2000-2009 (Source: Chicago Board Options Exchange). Panel B illustrates subprime mortgage AAA-tranche pricing in 2007-2008. The figure charts the AAA-tranche of the ABX index of the 2006 and 2007 first and second half of the year series from January 1, 2007 to December 31, 2008. The $A B X$ index is an index of 20 representative collateralized debt obligations (CDOs) of subprime mortgages. The AAA-tranche represents an initial equally-weighted portfolio of these same tranches of each CDO (Source: Markit).

Panel A: Subprime mortgage AAA-tranche pricing in 2007-2008. (Source: Markit)

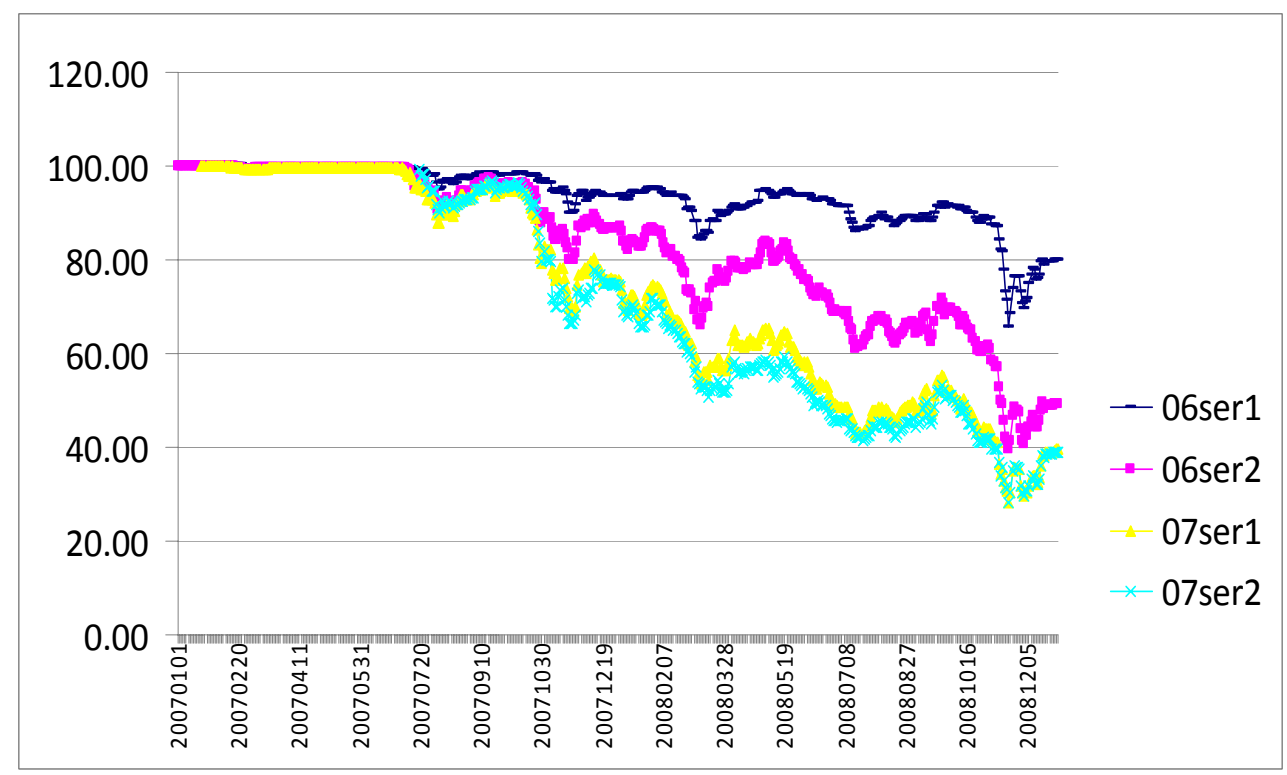

Panel B: Behavior of VIX, the option-implied measure of volatility during 2000-2009 (Source: Chicago Board Options Exchange)

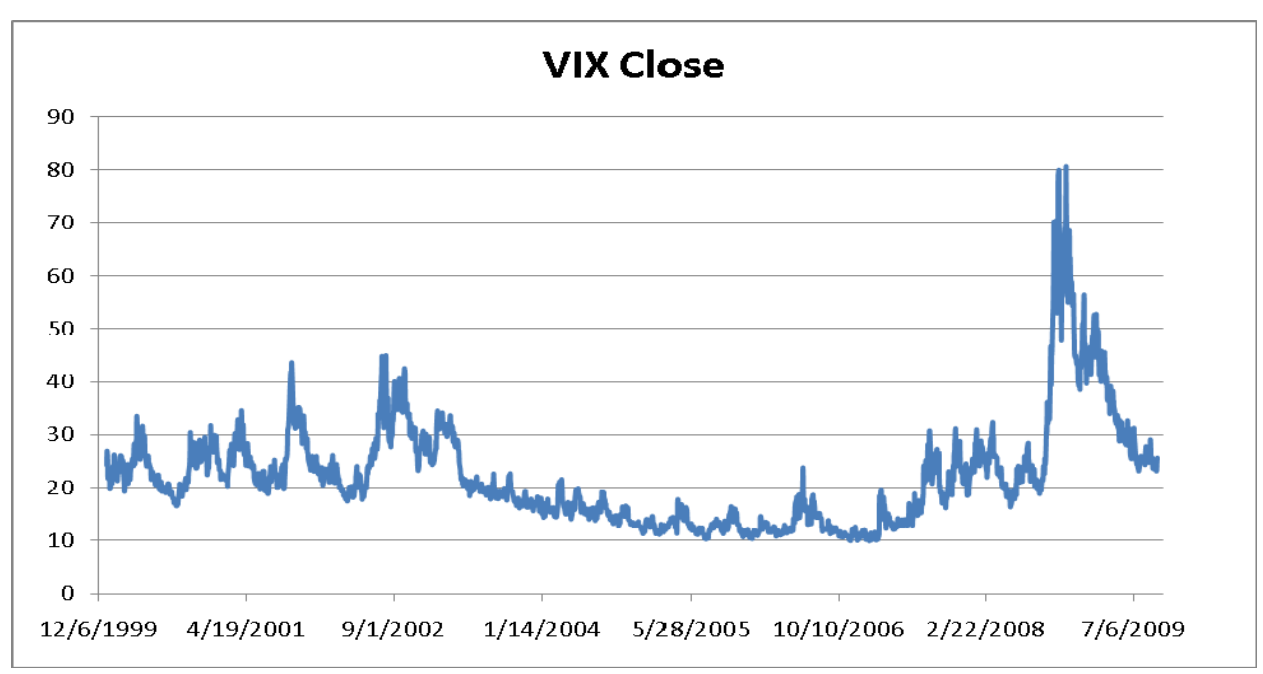




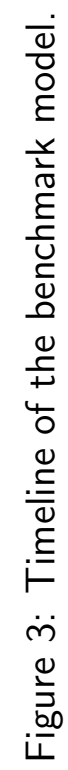

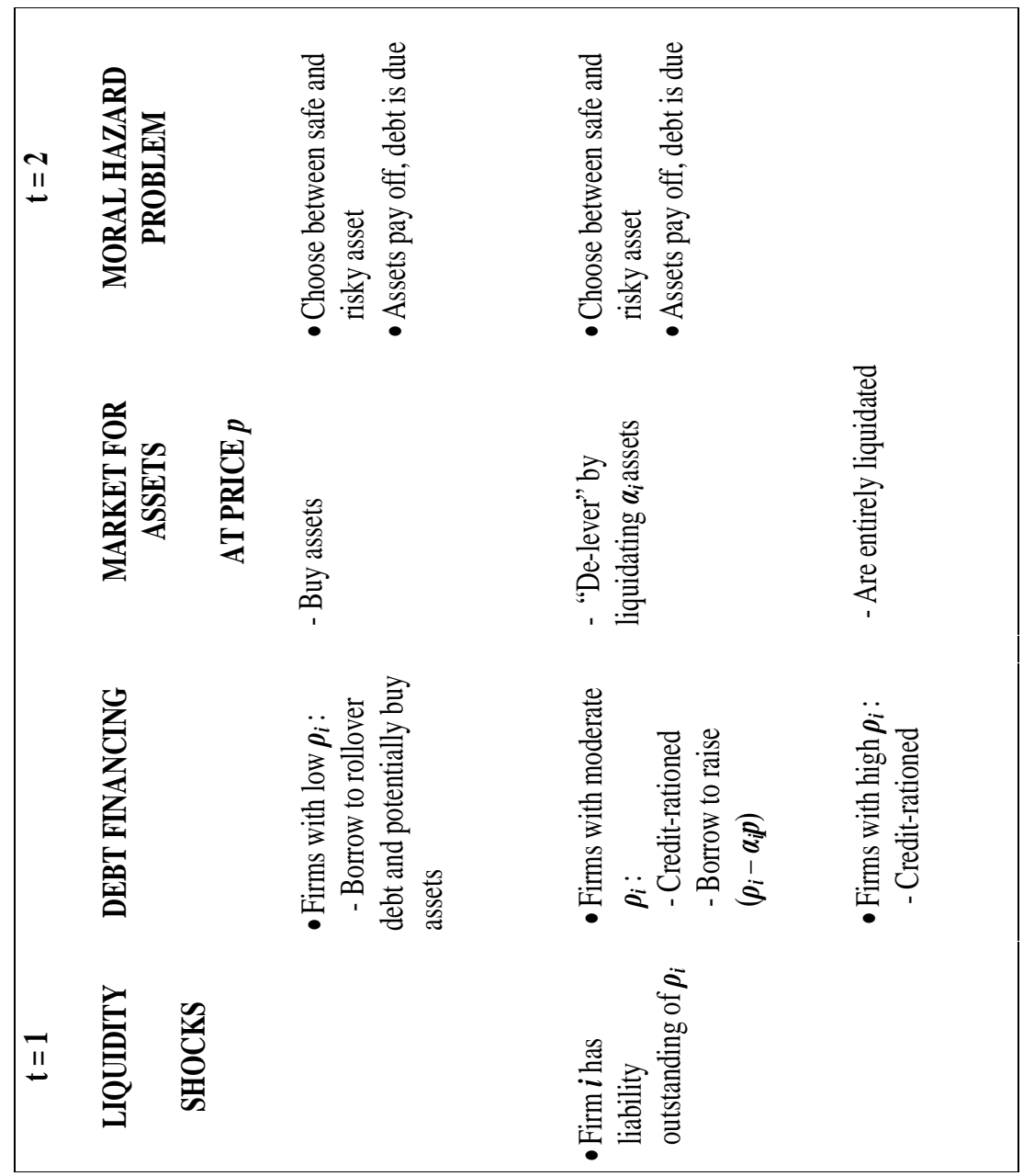


Figure 4: Effect of funding liquidity on equilibrium price, de-leveraging, market liquidity

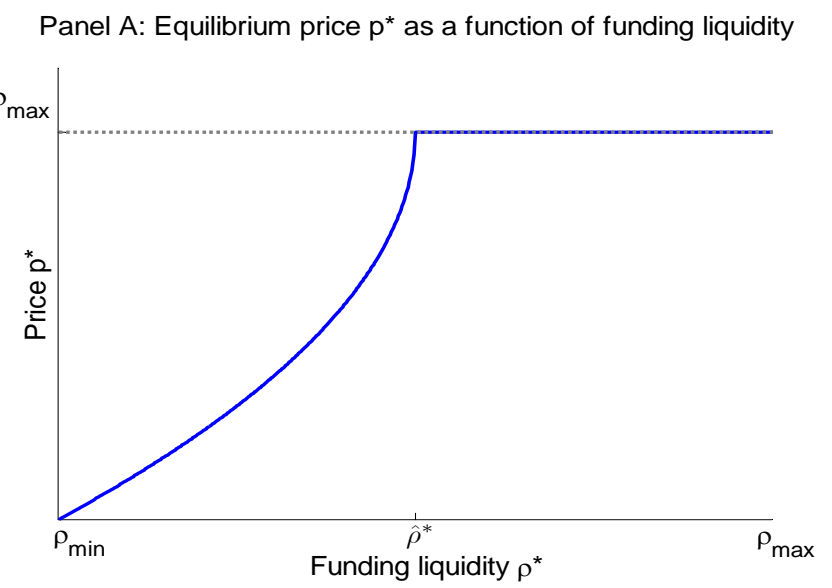

Panel B: Equilibrium de-leveraging or asset-sale proceeds as a function of leverage $\rho$

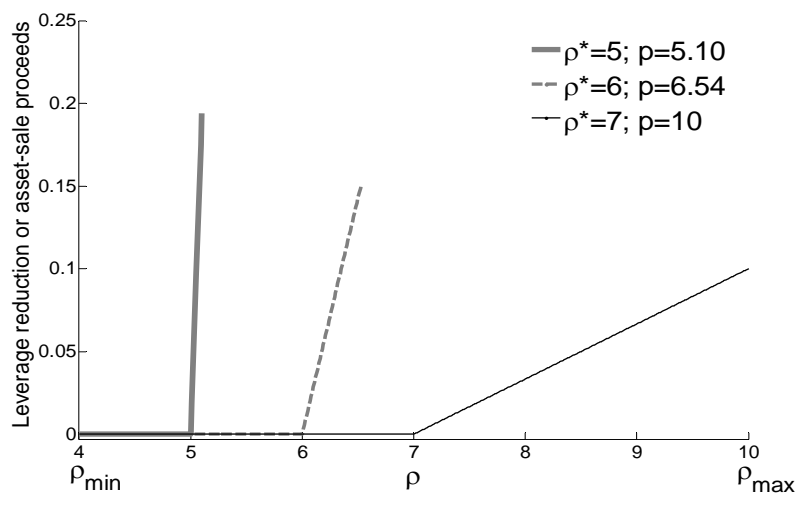

Panel C: The relationship between market (il)liquidity and funding liquidity

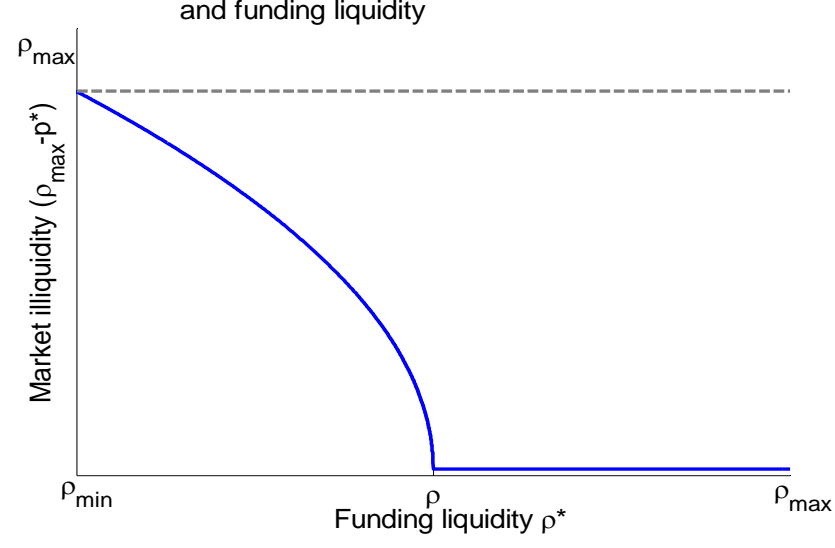




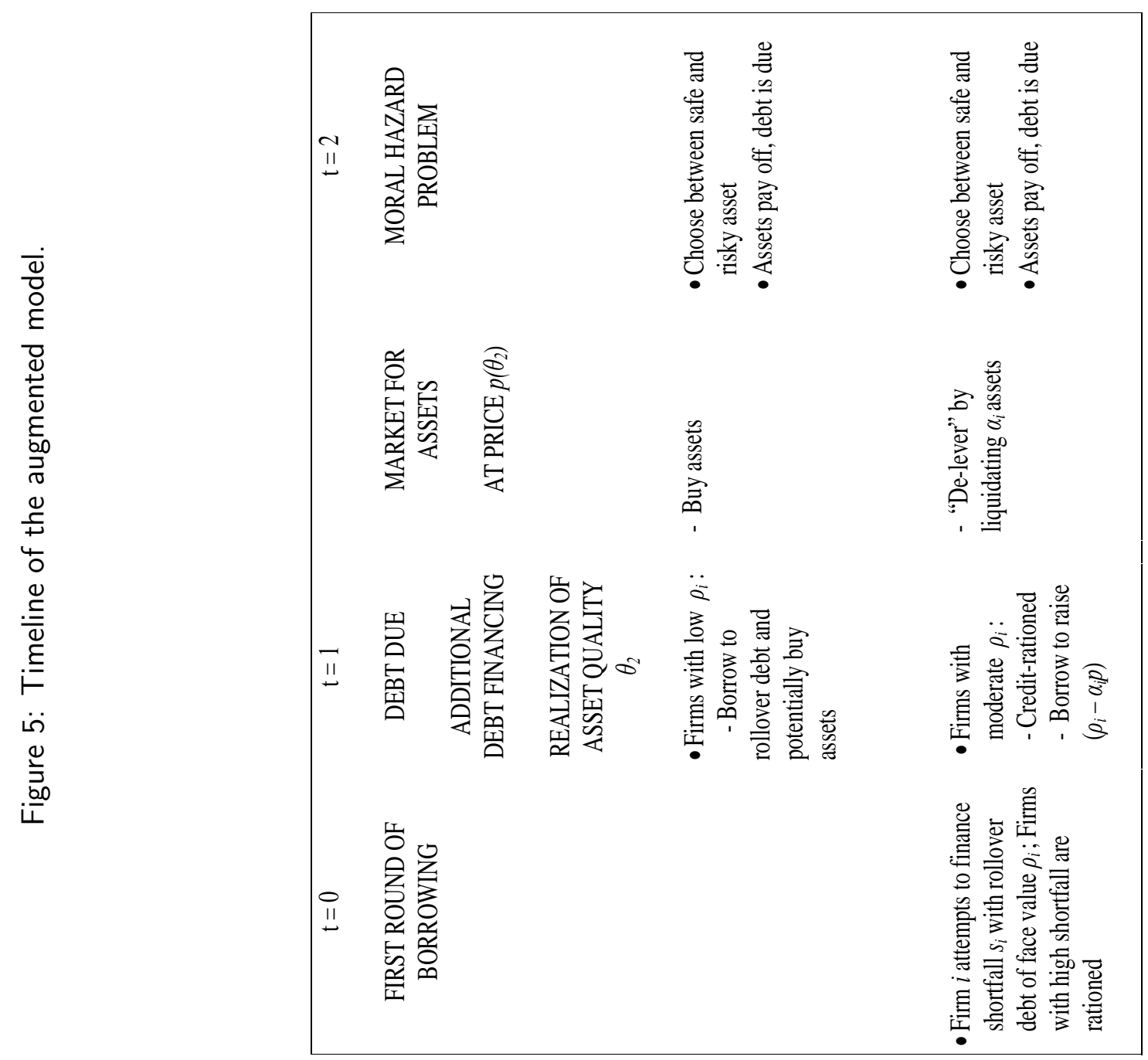



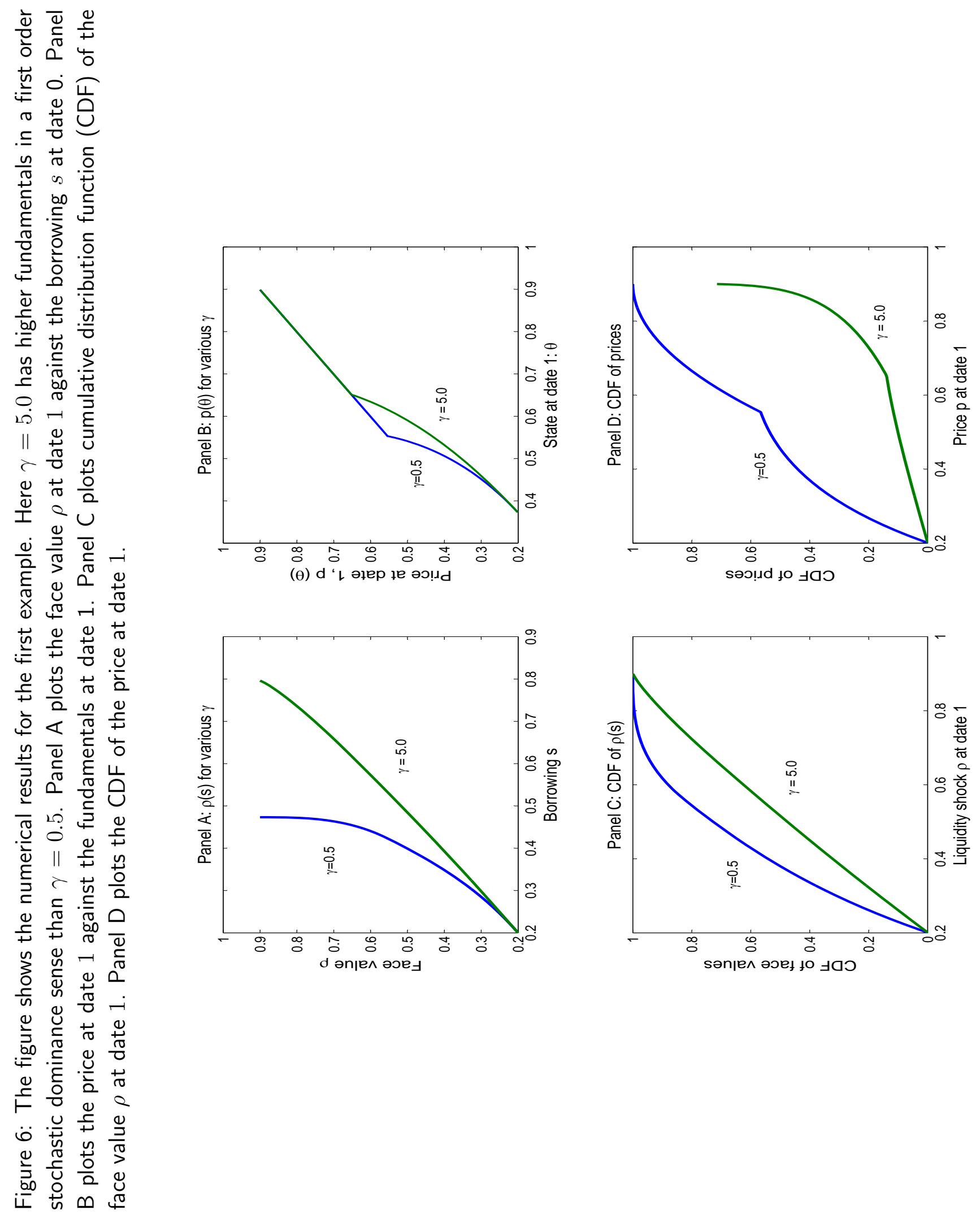

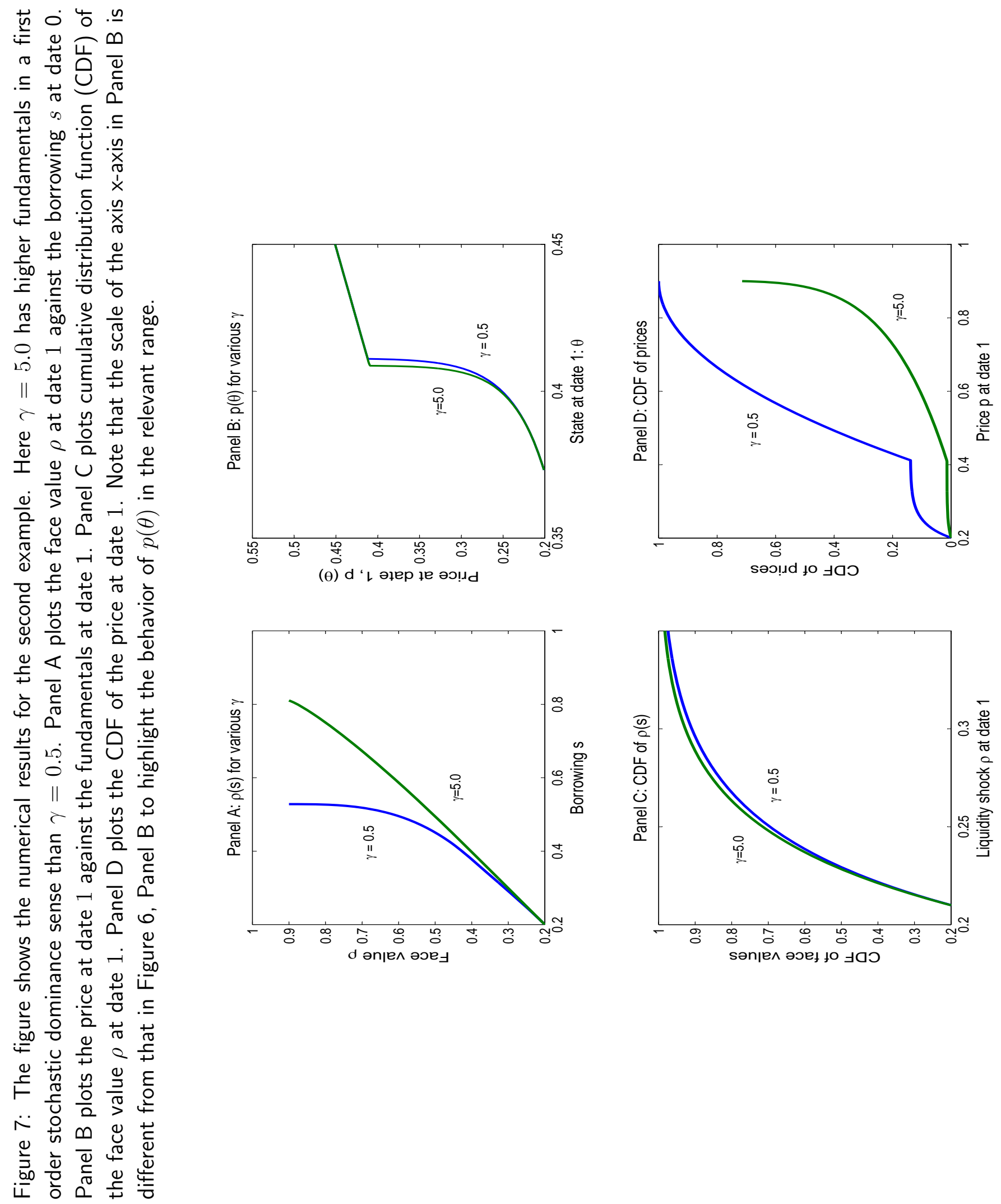